\title{
International Journal of Agricultural Sustainability Who determines the trade-offs between agricultural production and environmental quality? An evolutionary perspective from rural eastern China --Manuscript Draft--
}

Full Title:

Manuscript Number:

Article Type:

Keywords:

Abstract:

Order of Authors:

Response to Reviewers:
Who determines the trade-offs between agricultural production and environmental quality? An evolutionary perspective from rural eastern China

\section{TAGS-2018-0323R1}

Original Article

China; social-ecological systems, ecosystem services; evolutionary frameworks; trade-offs

We explore the evolutionary nature of interactions between government policy, farm decision-making and ecosystem services in Shucheng County, Anhui Province from 1950 to 2015. Analyses of ecological, social and economic trends are complemented by interviews with local farmers about their status, perceptions and attitudes. Since the introduction of the Household Responsibility System in 1980, the start of liberalisation, there has been a trade-off between rising levels of provisioning services and falling levels of regulating services in the environment, with some evidence that critical thresholds have been passed for water quality. Using a Framework for Ecosystem Service Provision, we argue that farmers have acted only as ecosystem service providers and have not influenced the national/regional policies that have brought about the trade-offs. Over the whole period, ecological degradation is best described as an example of 'creeping normalcy' where cumulative conventional actions by individual farmers produce unsustainable losses in regulating services. The Chinese government should be acting to balance the various ecosystem services through valuation and national policy. In this respect, there is a need for a new coordination of agencies that can deliver scientific and place-based advice to farmers that will allow them to maintain productivity levels while pursuing restorative actions. Even with new policies, the draw of urban employment and high production costs threaten the viability of farming in these marginal agricultural areas, especially over the next 10-15 years when most current farmers will retire.

John Dearing

Ke Zhang

Weidong Cao

Terence Dawson

David Armstrong McKay

Paul Sillitoe

Richard Treves

Xiangdong Yang

Ref.: Ms. No. TAGS-2018-0323

Who determines the trade-offs between agricultural production and environmental quality? A rural case study from eastern China

International Journal of Agricultural Sustainability

Authors' responses to Editor's/Reviewer's comments

We thank the Editor and Reviewers for their comments that we agree will help improve the paper. Our response to each point raised is shown in italicized text below.

1.Please remove 'case study' from the title.

Author response: We have changed the second phrase to "An evolutionary perspective 
from rural eastern China"

2.The quality of the figures is very poor - this needs revision before the text goes to production.

Author response: We provide new high resolution files for each figure and have dealt with issues raised by Reviewer 2 below.

3. The reference list a little bit old(ish); please can you include up to date peer reviewed references including those published in 2019, throughout the text.

Author response: We have updated and added more recent references.

Reviewer \#1: This is an excellent paper that is recommended for publication without revision.

\section{Reviewer \#2:}

The paper is well presented and supported by a relevant bibliography. The figures are helpful, but in the pdf provided, the colours used result in poor differentiation and should be modified to make the trends easier to follow. The explanations of each should also be presented below each figure.

Author response: We have modified figures 3, 4 and 5 to make the lines more distinctive. Figure captions follow the Appendix and full explanations of each figure are given in the text. .

The paper follows the impact of policy, markets, and farming practices on livelihoods and environmental services over 6 defined phases pre- and post- the introduction of the Household Responsibility System on 1980. While to principal policy differences between the phases are outlined, given the significance of the HRS as the prime driver of change, the paper would benefit from a better description of all the elements of the HRS beyond the specific policy changes listed for each phase.

Author response: We have added new text (especially lines 153-158) to give more information about Phase I and Phase II (HRS)

Using lake water quality and sediment cores to track environmental change and as means to validate farmers perceptions is novel and valid. The separation between lowland and mountain communities shows an interesting differentiation in perceptions and farming practices. However given the challenges presented by urban migration and aging it might have been useful to have investigated whether women or younger interviewees held differing views/perceptions.

Author response: Yes with hindsight this would have been a good idea.

The findings and conclusions appear consistent with the data presented. They replicate trends found elsewhere in China - and globally. The paper claims that it will address 3 overarching question (74-82). It demonstrates clearly that farmers are rational and responsive to national policy changes and market opportunities. The survey shows that farmers are aware of changes in their environment; however the paper fails to record how farmers are responding to, or trying to address impacts of their practices on the regulating services.

Author response: We dispute this to some extent because we do record that farmers see the problems of deteriorating regulating services as a governmental responsibility. In the section 'Views on ecological degradation' we state "......discussions with farmers revealed a dominant view that the responsibility for the degradation lies with the government, not with farmers themselves." The bottom line is that we have little evidence that farmers actually do address the impacts of their own actions. However we do agree that this point should be emphasized and have added new sentences to this effect (Lines 562-564; 618-622; 655-657) in the Discussion and Conclusion.

Finally while advocating institutional and policy reform to address environmental challenges, the authors do not suggest how/what these might be - eg through PfES, 


\begin{tabular}{|l|l|}
\hline $\begin{array}{l}\text { education, publicity campaigns, regulation. Or precision and conservation agricultural } \\
\text { techniques. }\end{array}$ \\
$\begin{array}{l}\text { Author response: We feel that these dealing with issues in more detail are beyond the } \\
\text { scope of the present paper and constitute substantial topics in themselves. Any one of } \\
\text { these topics could form the basis of another paper and some would require further } \\
\text { research and fieldwork. We would prefer to leave these parts of the discussion } \\
\text { unchanged. }\end{array}$ \\
\hline Additional Information: & Response \\
\hline Question & 8464 \\
\hline Number of words & \\
\hline
\end{tabular}




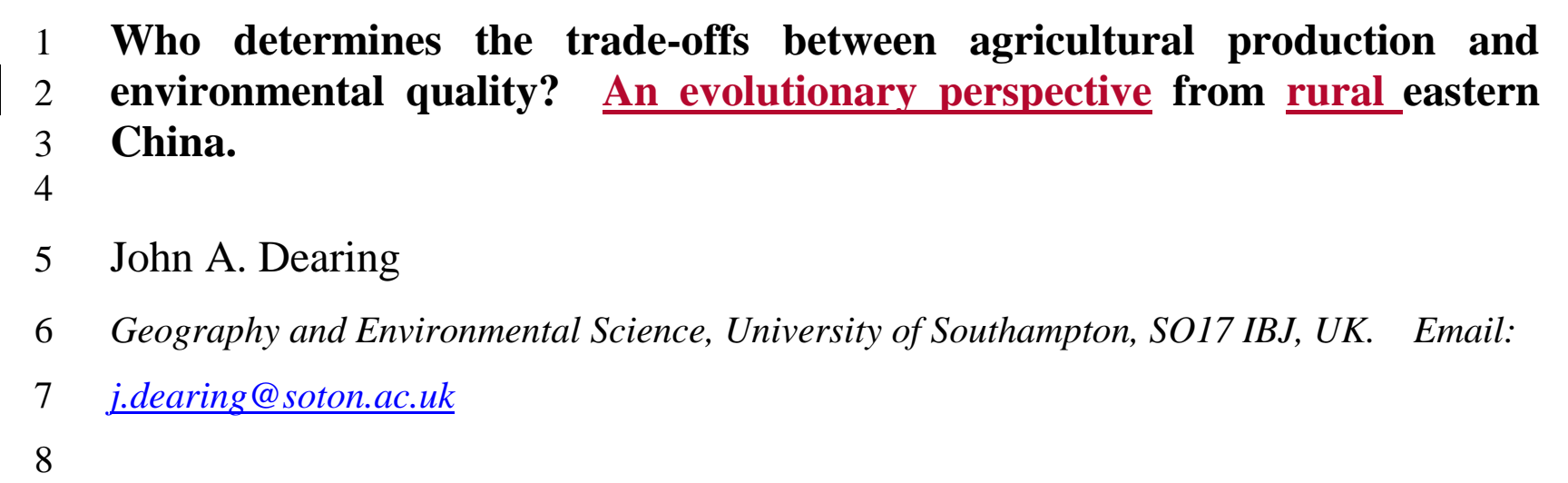

$9 \quad$ Ke Zhang

10 State Key Laboratory of Lake Science and Environment, Nanjing Institute of Geography and 11 Limnology, Chinese Academy of Sciences, Nanjing 210008, China. Email:

12 kzhang@niglas.ac.cn

14 Weidong Cao

| 15 School of Geography and Tourism, Anhui Normal University, Wuhu 241003, China. Email:

16 weidongwh@163.com

18 Terence P. Dawson

19 Department of Geography, King's College London, London, WC2R 2LS, UK. Email:

20 terry.dawson@kcl.ac.uk

22 David Armstrong MKay

23 Geography and Environment Science, University of Southampton, SO17 IBJ, UK

25 Paul Sillitoe

26 Department of Anthropology, University of Durham, 43 Old Elvet, Durham DHI 3HN, UK.

27 Email: paul.sillitoe@durham.ac.uk

29 Richard Treves

30 Geography and Environment Science, University of Southampton, SO17 IBJ, UK ${ }^{2}$

32 Xiangdong Yang

33 Nanjing Institute of Geography and Limnology, Chinese Academy of Sciences, Nanjing

34 210008, China. Email: xdyang@niglas.ac.cn 
36 Corresponding author: John A Dearing, Geography and Environmental Science, University of Southampton, Southampton SO17 1BJ, UK. Tel: +44 (0)2380 594648. E-mail: j.dearing@soton.ac.uk

${ }^{1}$ Now affiliated: Stockholm Resilience Centre, Kräftriket, 10405 Stockholm, Sweden. Email: david.armstrongmckay@su.se

${ }^{2}$ Now affiliated: The Open University, Walton Hall, Kents Hill, Milton Keynes MK7 6AA, UK. Email: richard.treves@open.ac.uk

\section{Abstract}

We explore the evolutionary nature of interactions between government policy, farm decision-making and ecosystem services in Shucheng County, Anhui Province from 1950 to 2015. Analyses of ecological, social and economic trends are complemented by interviews with local farmers about their status, perceptions and attitudes. Since the introduction of the Household Responsibility System in 1980, the start of liberalisation, there has been a trade-off between rising levels of provisioning services and falling levels of regulating services in the environment, with some evidence that critical thresholds have been passed for water quality. Using a Framework for Ecosystem Service Provision, we argue that farmers have acted only as ecosystem service providers and have not influenced the national/regional policies that have brought about the trade-offs. Over the whole period, ecological degradation is best described as an example of 'creeping normalcy' where cumulative conventional actions by individual farmers produce unsustainable losses in regulating services. The Chinese government should be acting to balance the various ecosystem services through valuation and national policy. In this respect, there is a need for a new coordination of agencies that can deliver scientific and place-based advice to farmers that will allow them to maintain productivity levels while pursuing restorative actions. Even with new policies, the draw of 
63

urban employment and high production costs threaten the viability of farming in these marginal agricultural areas, especially over the next 10-15 years when most current farmers will retire.

Keywords: China; social-ecological systems, ecosystem services; evolutionary frameworks; trade-offs.

\section{Introduction}

Warnings about the possible long term negative consequences of unsustainable farm practises (Raudsepp-Hearne et al., 2010) are partly borne out by global figures that show widespread stagnation and declines in grain yields (Mehrabi et al., 2019; Ray et al., 2012). However, the whole process through which agriculture is deemed to lie on a sustainable trajectory or not is complex. Sustainable agriculture depends not only on current top-down government policy and resource management strategies (Foley et al., 2011) but also on bottom-up decisions made by farmers in the light of national policy, markets and their knowledge about the environment (Duong et al., 2019; Fairweather et al., 2008). Farmers make decisions in response to less predictable short-term factors (Darnhofer et al., 2011), such as extreme climate events and energy costs, as well as to the likely impact of longer term trends, such as the emphasis in many countries on increasing crop yields through agricultural intensification (Garnett et al., 2013; Poppy et al., 2014; Pretty et al., 2018). In these ways, agriculture may be viewed as a complex system of ecosystem services with exogenous and endogenous drivers and pressures working through feedback mechanisms over a variety of timescales (Armstrong McKay et al., 2019; Zhang et al., 2018). 
In the People's Republic of China, agricultural output in the period 1950-2015 rose five-fold (Li et al., 2013). This has been achieved through technological advances, including new high yielding crops, mechanisation, fertilizers, pesticides and irrigation. In addition, policy reforms have moved farming away from collective systems towards more independent commercial regimes. Government policies since 1979 mainly reflect two sets of concern: maintaining or increasing crop yields, particularly grains, and reducing the incidence of hazards, like flooding and soil erosion. In ecosystem service terms, these different motivations have focused on extracting provisioning goods and services, and on protecting regulating services respectively. However, despite efforts to protect the environment, the growth in production has been linked to widespread ecological degradation, particularly soil erosion, salinisation, desertification and water pollution (Liu \& Diamond, 2005).

Our recent studies have highlighted the long-term trade-off between growing provisioning services and declining regulating services within the lower Yangtze basin (Dearing et al., 2012a; Lin et al., 2019; Zhang et al., 2015), and the widespread irreversibility of environmental degradation across China (Zhang et al., 2016). Indeed, a major challenge for Chinese agriculture is to find ways of maintaining or growing outputs while stabilising or reducing the ecological impacts. Chen \& Du (2014) suggest that the socio-economic constraints could be reduced with economic development and changes in land tenure and land management. But to do this requires more detailed information about how past policies and reforms have affected the social-ecological systems in rural China.

Here we focus on one of those areas in the lower Yangtze basin, Shucheng County (hereafter Shucheng) in order to try and understand how trade-offs between rising production and deteriorating environmental quality have reflected the interaction of national agricultural 
112 policy and local farming decisions. Shucheng is an agriculturally marginal 'poverty-stricken'

113 county with low levels of income, offering a chance to observe the environmental constraints

114 on long term economic growth and poverty alleviation, and the possible negative

115 consequences of environmental degradation. We have designed a research methodology that

116 addresses the following overarching questions:

117

$118 \bigcirc$ How have national policies affected farming decisions and ecosystem services through

119 time?

120

$121 \quad$ Were local farmers able to perceive the environmental degradation and make restorative $122 \quad$ actions?

- Given the findings, what are the implications for designing or implementing appropriate policies over the next thirty years?

\section{Materials and Methods}

\section{Shucheng County}

131 Shucheng (area $2092 \mathrm{~km}^{2}$ ) lies to the west of Chaohu lake in Anhui Province (Figure 1). The

132 landscape of the county comprises the Dabie Mountains (52\% area) in the west, a central hilly

133 area (20\% area), and alluvial plains (28\% area) extending to the lake edge. The population of

134 the county doubled between 1950 and 2000, from 489500 to 983379 (Chorography

135 Compilation Committee of Shucheng County, 1995; Yan et al., 2009), and is currently 1

136 million with $86 \%$ engaged in agriculture. As a result of reforestation since the $1960 \mathrm{~s}$, the total 
area under cultivation decreased from $507 \mathrm{~km}^{2}$ (1950) to $416 \mathrm{~km}^{2}$ (2009). The Green for

138 Grain Programme (1999-2007) gave payments across China for ecosystem services in order to

139 convert croplands on steep slopes to forest (Liu et al., 2014). Main crops are rice, wheat,

140 cotton and rapeseed in the plains with rice, tea and chestnuts in the mountains, and vegetables

141 near major towns. Labelled by the national government as one of the $\sim 590$ 'poverty-stricken'

142 counties of China, an annual farmer's income was (in 2008) approximately US\$ 900. Despite

143 reforestation of up to $65 \%$ of the steep slopes in Shucheng (Yuan et al., 2014; Yu, 2011;

144 Zhang et al., 2010), soil erosion, river sedimentation, flooding and water pollution have at

145 various times become serious problems (Dai et al., 2009), undermining poverty reduction

146 activities and sustainable rural development.

148 Chinese agricultural policy 1949-2011

149 Since 1949, farmers in Shucheng, as in every Chinese county, have worked under the direct

150 influence of national agricultural policy. Li et al. (2013) define six historical phases of

151 national agricultural policy aimed at influencing grain production. From Phase I (1949-1977)

152 to Phase VI (2011 onwards) there was a shift of direct control and responsibility from the

153 government to the household. Phase I was a collectivised economy where farmers were given

154 quotas for food production but no extra compensation for producing beyond the quota. The

155 introduction of the Household Responsibility System (HRS) at the beginning of Phase II in

1561978 reallocated land rights from the People's collectives to individual farms with the

157 opportunity for farmers to sell surplus produce at a market price. During Phase II, farmers'

158 quotas were reduced which gave further incentives to produce crops for sale at market prices.

159 Phase III extended the liberalisation process with promotion of pesticides and fertilizers and

160 non-grain cash crops through price controls. Phase IV (1999-2003) saw a drop in national

161 grain production as farmers shifted their focus towards cash crops in response to the 
162 government leaving grain prices to be controlled by the market. In order to restore grain

163 production, in 2004, the government removed agricultural tax and introduced subsidies for

164 grain production (Phase V). Although national figures for grain production have been revived

165 by these measures the rates of increase since then (Phase VI) are low relative to the large

166 inputs of fertilizer and other resources (Li et al., 2013). The ongoing response to 'inefficient

167 farming' is the reform of land management through Land Circulation (Li, 2010) involving

168 aggregation of small fields into larger units that is designed to improve the economies of scale 169 and incomes.

170

171 Some national fluctuations in historical grain production figures are therefore explained by 172 changes in national policy (Xu et al., 2014). However, since 2000, there have been notable

173 short- term fluctuations in annual yields that have led to speculation that agricultural

174 production in some regions is now biophysically constrained by resource depletion, such as

175 groundwater (Brown, 2013) or positive feedback mechanisms, like soil acidification (e.g. Guo

176 et al., 2010). Other commentators (e.g. Li et al., 2013) argue that the slow increase in grain

177 production in recent years is due to the lack of modern agricultural technology and methods.

178 Indeed, results from field experiments across China (Chen et al., 2014) suggest that current

179 yields of rice, wheat and maize could be raised by $18-35 \%$ through the adoption of integrated

180 soil-crop system management practices though the results of a major field campaign trial puts

181 these figures at a lower level, at about 11\% (Cui et al., 2018).

182

\section{Study approach}

184 We take an evolutionary approach (Dearing et al., 2012b) that combines information on

185 changes in national policy, farm activities and ecosystem processes over 65 years together

186 with the views of current farmers. An evolutionary perspective is important for identifying the 
timescales of drivers, ecosystem states and human responses, understanding the nature of

188 trade-offs between ecosystem services, and evaluating the extent to which a social-ecological

189 system is contingent on past events and conditions, or even path-dependent. Such

190 information can also help identify whether detrimental transitions (tipping points) in, for

191 example, productivity or ecological states, have already occurred or inform on the likelihood

192 of thresholds being transgressed in the near future. Transitions are often relatively rapid but

193 may be the culmination of slow incremental change in some key process that are

194 imperceptible without long term ecological monitoring (Zhang et al., 2007; Zhang et al. 2015),

195 and may be costly to fix or even irreversible (Scheffer et al., 2012). In order to facilitate

196 analyses, we embed the evolutionary approach within a Framework for Ecosystem Service

197 Provision (FESP - Rounsevell et al., 2009) based on a modified Driver-Pressure-State-Impact-

198 Response $^{1}$ (DPSIR) framework (Figure 1). The FESP integrates across multiple services and

199 scales, makes explicit the exogeneous and endogenous drivers within the system, and,

200 importantly, allows for feedback mechanisms that drive non-linear interactions.

202 Annual statistics for agriculture, population, economy and climate are available at provincial

203 (1949-2008) and county levels ( 1980s to 2008) giving time-series for provisioning

204 ecosystem services and socio-economic-environmental drivers, but ecological monitoring of

205 water quality and other ecological processes are, at best, available for recent years only.

206 Regulating services are the most important in terms of determining the sustainability of land

207 systems but are often poorly understood or under-represented in studies because of

208 insufficient data. Therefore, we use laboratory analyses of lake sediments to allow the novel

209 historical reconstruction of multi-decadal trends in major regulating ecological services within

210 the upstream catchment and lake (Dearing et al., 2012a). Here, we use dated sediment cores

\footnotetext{
${ }^{1}$ Throughout the text we capitalize the first letter of terms referenced within the FESP.
} 
sampled from Chaohu lake as proxies for decadal time-series of water quality, lake

212 productivity, air quality, sediment quality, terrestrial biodiversity and soil stability.

214 We first describe the multi-decadal trends and use principal component analysis (PCA) and

215 breakpoint analyses to reveal plausible long-term associations between Drivers, Pressures,

216 States and Impacts (Figure 2). Second, we compare the temporal data against shorter term

217 policy changes to tease out plausible links between Responses (policy decisions), Pressures,

218 Impacts and States. Third, we interrogate the links between human behaviour and ecosystem

219 services within States and Impacts through the results of a questionnaire survey, exploring

220 how changes in ecosystem services are perceived by local farmers, how they currently assess

221 their farming in terms of policy and income, and how they are planning for the future.

222 Finally, we draw the findings together in addressing the research questions.

\section{Time-series data and statistical analyses}

225 Official annual statistical data for social, economic and agricultural changes were obtained for 226 Shucheng, Anhui Province, and an average for of all China's Provinces from Statistical Year 227 Books. Climate data were obtained from monitoring records in the nearby Hefei City located $22850 \mathrm{~km}$ to the northeast of Shucheng (Figure 1). Sediment data were obtained (see Dearing et 229 al. 2012a for full details) from sediment cores taken from the western side of Chaohu with a 230 piston corer in 2006. Core sediments were subsampled at a $0.5 \mathrm{~cm}$ resolution for $0-50 \mathrm{~cm}$ and

$2311 \mathrm{~cm}$ resolution in deeper sediments. Sediment samples were dated using ${ }^{210} \mathrm{~Pb}$ and ${ }^{137} \mathrm{Cs}$ 232 radioisotopes, and a constant rate of supply model was used to calculate a chronology and 233 depth-age curves for each core. Only data in the period 1950-2006 are used in the present 234 study. Typically, the dating errors are \pm 5 years ( 2 st. dev) for 1950 reducing to \pm 2 years in 
recent years. The sediments were analysed to produce the following proxies for ecosystem

236 services:

- Sediment regulation proxy: dry mass sediment accumulation rates (SAR)

- Soil stability proxies: magnetic susceptibility and the $\mathrm{Sr} / \mathrm{Rb}$ geochemical ratio.

- Air quality proxies: lead $(\mathrm{Pb})$ and soot concentrations.

- Water quality proxies: diatom inferred-total phosphorus and total organic carbon (TOC).

- Biodiversity proxy: rarefaction indices for floristic richness in pollen counts.

Normalised data varying between 0 and 1 are used (Figure 3 ) so that trends can be easily

244 compared and aggregated. The formula used for scaling the data series $(\mathrm{x} 1: \mathrm{xn})$ to $(0: 1)$ is $\mathrm{x} 1$ -

$245(\min x 1: x n) /[(\max x 1: x n)-(\min x 1: x n)]$ where $\min$ and $\max$ are minimum and maximum

246 values within the data range. In the case of biodiversity, values of 1 and 0 equate to highest

247 and lowest levels of ecosystem service. For all other proxy records, like soil stability, values

248 in the range 1 to 0 were inverted so that values of 1 and 0 equate to highest and lowest levels

249 of ecosystem service respectively. Principal components analysis of the time-series data was

250 performed and plotted by the prcomp and ggbiplot functions in R (

251 Statistically significant $(\mathrm{p} \leq 0.01)$ breakpoints in time-series were calculated (Zhang et al.,

252 2015) as evidence for shifts in system or sub-system states.

\section{Questionnaires and focus groups}

255 A questionnaire with closed and open questions was designed (see Appendix) to obtain 256 information about current farming activities, farmer's perceptions of ecological degradation 257 and their future plans. Farmers were selected randomly from towns situated in the two most 258 contrasting landscape-farm systems across the county (Figure 2): mountains (Hepeng) and 259 plains (Hangbu). The survey, conducted in August 2012, was administered to 68 farmers (33 
from Hepeng and 35 from Hangbu). Trained university research students conducted face-to-

261 face interviews with farmers at their house or at local agricultural offices, where interviews

262 typically lasted 30 minutes. All the interviews were conducted on a voluntary basis, and

263 farmers consented verbally to a written set of survey aims and the anonymous use of the 264 collected data.

\section{Results}

Trends and statistical analyses

Trends for the main Drivers, Pressures and Impacts within the system show (Figure 3) rising trends for population from 1949, GDP/capita from the 1990s (when records began), fertilizer applications from 1990 (when records began), and mean annual temperature from the 1980s. In contrast, the proportion of the rural population has steadily declined since the 1980s, as has the area of cultivated land that declined rapidly in the 1960s and again in the 2000s.

The multi-decadal data for States of ecosystem services (Figure 4) clearly show two sets of 275 broad trends. Provisioning services show generally increasing trends over the whole period starting in 1950 (grain, pigs, tea) or from the 1990s (fruit, aquatic products and timber). In contrast, regulating services show generally decreasing trends, particularly from the 1970s (soil stability- $\mathrm{Rb} / \mathrm{Sr}$ ratio, air quality, water quality) and 1990s (terrestrial biodiversity) onwards. The period 1950-1980 shows stable or even improving (terrestrial biodiversity)

280 regulating services (Figure 4).

282 PCA for the dataset (Figure 5) shows PC1 accounting for $\sim 58 \%$ of the explained variance controlled by cultivated land area opposing many of the other records, especially crop yield, 284 population, air quality $(\underline{\mathrm{Pb}})$, soot, tea, soil instability, fertilizers, total lake water phosphorus, 
fruit and pigs. PC2, with $\sim 12 \%$ variance, shows temperature opposing precipitation, soil 286 instability (Xd $\%$ ) and biodiversity. PCA analyses identify three clusters representing the 287 periods 1959-1968, 1969-1993 and 1994-2006 which map onto the Great Leap Forward and 288 the 1960s, the Cultural Revolution and early HRS period, and the later period of HRS with 289 rural market liberation and onwards (Table 1). These three periods shift from initial 290 associations with high levels of cultivated land and relatively low yields, to associations with 291 climate, soil erosion and biodiversity, to the most recent associations with relatively high 292 yields and poor air and water quality. An alternative analysis, for the 1952-2011 dataset, gives 293 PC1 with $67.7 \%$ of the explained variance with cultivated land area opposing yield, 294 population, pigs and yield (kg/ha). PC2 with $\sim 11.3 \%$ explained variance shows temperature, 295 timber, aquatics and fruit opposing precipitation. The pattern of samples shows three broad 296 time periods dominated by 1952-1968, 1969-1996 and 1997-2011. For 1991-2011, PC1 with $29751.4 \%$ of the explained variance shows cultivated land area opposing total population, 298 temperature, aquatic, fruit, GDP and yield (kg/ha). PC2 with $\sim 18.6 \%$ explained variance 299 shows rural population opposing pigs and precipitation. The pattern of samples shows three 300 broad time periods dominated by 1991-1998, 1999-2006 and 2007-2011 which more or less 301 map onto the later period of HRS with rural market liberation, HRS grain policy and HRS subsidy policy.

Results of the breakpoint analysis for all the time-series identify (Zhang et al., 2015) abrupt 305 changes in lake water quality in 1979 and in aggregated regulating services in 1977 broadly at 306 the time of the early HRS. Breakpoints in provisioning service series are less clear but there 307 is evidence for shifts during three periods: the Cultural Revolution in the mid-1960s to the 308 early 1970s, the HRS of the late 1970s to early 1980s, and the HRS with rural market 309 liberation in the mid-1990s. 
311 Overall, the visual and statistical analyses of broad trends provide the following insights:

312 - Long term rises in provisioning services contrast with long term declines in several

313 indicators of regulating services;

314 - The analyses describe a 'land use intensification' process involving greater provisioning

315 of agricultural and aquatic products from a reducing farmland area involving a smaller

316 proportion of the population, and environmental degradation through losses of soil, air and

$317 \quad$ water regulating services;

318 - Together, these findings point to a long-term trade-off between successful agricultural

319 production driven largely by improved farm technologies, and environmental

320 deterioration;

- Successful agricultural production has been associated with rising total populations and

322 total incomes (GDP/capita) even as the proportion of the rural population declines;

323 - Losses of ecological resilience and transgression of thresholds in natural ecosystems

324 reached their peak during the 1970s;

325 - Statistically, the social-ecological system has evolved through three states seemingly

326 determined by major national policy Responses associated with the Great Leap Forward,

327 the Cultural Revolution and early HRS, and the later HRS with market liberation.

328 - The 'early HRS' and the later 'HRS with market liberation' periods are linked to abrupt

329 changes in regulating and provisioning services that may indicate the transgression of

$330 \quad$ thresholds. 
This section focuses on the shorter-term associations between national policy Responses and

334 local changes in social-ecological States and Impacts. Organised by the first five phases of

335 policy, it refers to key dates and trends (Figures 3 and 4) described in section 3.

\section{Phase I Government control (1949-1977)}

338 The early period of direct government control (Table 1) is notable for two major political

339 initiatives that affected farmers: the Great Leap Forward (1958-1961) and the Cultural

340 Revolution (1966-1976). The beginning of the Cultural Revolution maps on to the boundary

341 between two PCA clusters in the late 1960s suggesting that the Cultural Revolution

342 represented a major shift in the Response-Pressure-State connections within a single phase of

343 national policy. In Shucheng, the rise in rural population after 1949 plateaued after 1955 and

344 fell to a temporary minimum during the Great Leap Forward. This period is associated with

345 the highest recorded cultivated land area, reduced terrestrial biodiversity and loss of soil

346 stability (in two out of the three proxies) as the steeper marginal slopes were opened up. This

347 is consistent with documented deforestation before the 1970s in the upper Hangbu (Dai et al.,

348 2009) where forest area declined from $60 \%$ in the early 1950 s to $27 \%$ in the mid-1970s and

349 was associated with high levels of soil erosion. From 1964, the rural population rose again

350 with increasing production of grains, aquatic products, tea and pigs; changes that create the

351 first statistically significant shift in provisioning services. The following period, the Cultural

352 Revolution, saw declining cultivated areas, recovering levels of terrestrial biodiversity, rising

353 pig and aquatic production and seemingly increased soil stability. However, recovery of soil

354 stability after the Great Leap Forward may be misleading because the Longhekou reservoir

355 (built in 1958) will have trapped much of the sediment from the upper catchment. The

356 reservoir sediment records show highest values for surface soil erosion in the mid to late

357 1970s (Dai et al., 2009) that coincide with the end of a seven-year period (1970-1977) in 
which there was a 4-fold increase in the area under tea plantations. Tea plantations are often situated on steep slopes to aid drainage, maintained with no ground cover, and liable to severe rilling. The move to increase tea plantations suggests that some land use diversification and

361 farm income generation was occurring at the start of the Cultural Revolution before the 362 introduction of the HRS, effectively creating a new social-ecological State. The impact of 363 Phase I policies on farming and ecosystem services was therefore varied. It occurred largely 364 through the direct encouragement of early deforestation of marginal mountain slopes to raise crop production but ultimately led to the expansion of tea plantations. To what extent the tea expansion was nationally directed or locally determined is not known.

\section{Phase II Household Responsibility System (1978-1984)}

369 The introduction of the HRS in 1978 (Table 1) is associated (Figure 3 and 4) with a constant 370 cultivated land area, and rising tea, fruit and pig production; changes reflected in the second statistical shift in provisioning services. The steady rise in grain production since 1965 slows during Phase II with a significant drop in 1980 that coincides with a peak in the measurement 373 of 'disaster area', possibly reflecting the lagged effect of the major drought in 1978. More

374 certainly, the start of the period is marked by statistical shifts in water and air quality suggesting that the deforestation in Phase I coupled to the start of rural industrialisation and agricultural intensification using artificial fertilizers in Phase II had major detrimental environmental impacts. Terrestrial biodiversity fluctuates around the levels seen in the later

378 part of Phase I but soil stability ( $\mathrm{Rb} / \mathrm{Sr}$ ratio) decreases further suggesting soil erosion had 379 extended from the mountains above the reservoir to other parts of the county. Two phases of 380 check dam building in the late 1980s (and later in Phase III) support the records for soil 381 stability and sediment regulation services (sediment accumulation rates) that show a major 382 decline through the late 1970s and 1980s as a result of continued accelerated erosion, despite 
reforestation schemes in 1976 and 1980. But overall, if Phase I was a period when policies destabilised soils and destroyed biodiversity, it seems that Phase II was the turning point towards destabilisation of air and water quality.

\section{Phase III HRS with rural market liberalisation policy (1985-1998)}

The period of 'HRS with rural market liberalisation' (Table 1) in Shucheng prior to 1997 is associated with a constant rural population and slowly increasing wealth, before a sharp increase in county GDP per capita in 1997-1998 as the rural population declines. Grain production also rises steadily from 1985 until a major decline in 1991, which is followed by a recovery and a return to just below former levels in 1998. Pig production rises steadily until the end of the period, aquatic and timber production both show sharp rises in the 1990s, but tea and fruit production show overall declines. These contrasting patterns of crop production are matched by large fluctuations in fertilizer usage. Interestingly, major statistical shifts in both provisioning services and the whole social-ecological State (Figure 5 and section 3 ) occur during the mid-1990s, suggesting a major change in Response-States connections within Phase III. Whatever the drivers of these changes, the ecological responses are equally diverse. One record for water quality (total organic carbon) shows rapid deterioration from the start of Phase III, but the other record (diatom-inferred total phosphorus) fluctuates about previous levels. One record for soil stability ( $\mathrm{Rb} / \mathrm{Sr}$ ratio) steadily declines through this period whereas the other record (magnetic susceptibility) fluctuates significantly in the period around 1990. There is strong evidence that some of the patterns in crop production and in the soil and water responses are climatically driven. The sharp drops in grain production and major fluctuations in soil stability at this time are consistent with the effects of the extreme rainfall and floods (1991-1992) and peak measurements of 'disaster areas' (1991-1995). Air quality continues to deteriorate in the first half of the phase before recovering and then falling 
back in the last years. Terrestrial biodiversity shows fluctuating values before falling rapidly

409 from a peak in 1994 that parallels the rise in timber production. Overall, Phase III is typified

410 by fluctuating patterns of crop production that may suggest a significant move towards

411 trialling different crops or farming techniques but may also reflect the impact of extreme

412 climate. Certainly, this phase sees the start of upward trends in the cash crops of timber,

413 aquatic and fruit, and a gradual contraction of the area under cultivation. These agricultural

414 changes continue to drive losses of regulating services.

415

Phase IV HRS with grain policy (1999-2003)

417 The end of Phase III is characterised by a fall in the rural population that stabilises in Phase

418 IV, the period of 'HRS with grain' policy (Table 1). Cultivated land area falls, grain

419 production fluctuates, grain productivity increases and fertilizer usage rises sharply before

420 falling indicating that more marginal land was abandoned. Meanwhile tea plantations show a

421 steady rise for the first time in $\sim 15$ years, and pig, fruit and aquatic production show

422 continuations of the rising trends that started in Phase III. This shift towards lower levels of

423 grain production as more profitable cash crops expand may explain the slow but steady

424 growth in county GDP per capita. But some of the fluctuations in the grain data may also

425 reflect the negative effects on agriculture by the major floods of 2002-03, which are marked

426 by peak values for measured 'disaster area'. Data for timber production drops during this

427 period and this may be reflected in the recovery in the records of terrestrial biodiversity.

428 Records of soil stability show evidence for a long-term recovery (in two of the three proxy

429 records) with an upturn in one of the records ( $\mathrm{Rb} / \mathrm{Sr}$ ratio). Water quality records now show

430 rapidly declining signals possibly responding to the high levels of fertilizer usage. Out of all

431 the regulating services, only air quality records show evidence for stabilised or constant

432 conditions. Overall, Phase IV describes a contracting agricultural area, shifts in the choice of 
crop production, the highest recorded fertilizer usage and significant negative impacts on water quality.

\section{Phase V HRS with subsidy policy (2004-2011)}

The introduction of an 'HRS with subsidy' policy in Phase V (Table 1) is associated with increasing size of cultivated land area, increasing rural population, increased tea plantation area, increased fertilizer usage, rising grain yields and productivity, rising aquatic and timber production, but steadily declining pig production. The main impacts on regulating services until 2006 (when records end) are further declines in soil stability, biodiversity and water quality. Water monitoring data (lake Chaohu) between 2003-2010 show relatively high but fluctuating values for total nitrogen and chemical oxygen demand, but rising values for total phosphorus that confirm the long term downward trajectory for water quality. Overall, Phase V shows the impetus to the rural population and crop production induced by subsidies, with the associated losses of soil stability and water quality services.

\section{Farmers'views}

This section describes the results of a farmer questionnaire analysis.

\section{Farm status}

The farms in the survey are small with an average area of $0.44 \pm 0.68$ ha (maximum 3.63 ha) supporting on average $3.7 \pm 2.2$ persons. Mountain farms are on average $38 \%$ smaller in area than the farms on the plain. The main crops are rice, wheat, cotton, rapeseed oil crops and maize $(22 \%)$ (Figure 6a) with less rice and more maize grown in the mountains. The farmers are typically middle-aged to old, with a mean age of $52 \pm 15$ years and modal peak $60-64$ years, having worked on the same farm for $23 \pm 15$ years (maximum 40 years). Around $70 \%$ 
have been educated only to primary school level. Only $19 \%$ stated that farming was their

459 main source of income, and 93\% have family members working in the town. Non-

460 agricultural income (as \% of their total income) is on average $77 \% \pm 18 \%$. Current

government subsidies received by the farmers range from zero to 6600 Yuan/yr ( 1090 USD) with an average $597 \pm 1106$ Yuan/yr ( 100 \pm 180 USD) largely determined by the farm size.

463 Subsidies to the mountain farms are on average $60 \%$ lower.

Views on farming

In general, the farmers' views on agricultural management are consistent across the groups from the mountains and plains. Not surprisingly, the overwhelming majority want to maximise profit and minimise risk. Over $90 \%$ of farmers are interested in how national agricultural policies and subsidy schemes apply to their farms, and a similar percentage keep track of market prices. A majority (71\%) would like to try out new agricultural ideas, like organic or precision farming, but a larger majority (90\%) think they lack the appropriate knowledge. Many farmers believe that resources for new methods are unavailable to them and are generally unprepared to invest time and money in new crops and equipment. It should be noted that there is a tendency for these attitudes to differ between the sub-groups. Farmers on the plain are the least convinced that extra resources are available but are more prepared to invest their own resources. They are also less inclined to change the land use when market

477 prices change. Overall, a majority of all farmers (69\%) do not believe that the government 478 offers opportunities for improving farm profits. It seems that the largest influences on an 479 individual farmer is the success of nearby farms. More than $75 \%$ of farmers would copy a neighbour's new activity if they saw that it was successful. 
The farmers rank water quality, drought and soil quality as the most important types of

484 ecological degradation and losses of regulating services (Figure 6b). But there are differences

485 in the sub-groups, with mountain farmers ranking drought and rivers running dry the highest,

486 and the farmers on the plain ranking water quality and soil quality the highest. Only $8 \%$

487 stated that there was no degradation. The whole group varies in identifying the main causes

488 of degradation as chemical fertilizer and pesticide use (Figure 5c), climate change, over-

489 cultivation, new crops/techniques and deforestation, with farmers on the plain emphasising

490 the importance of fertilizer and pesticides compared to the mountain farmers. Off-record

491 discussions with farmers revealed a dominant view that the responsibility for the degradation

492 lies with the government, not with farmers themselves. In the year preceding the survey,

$493 \sim 60 \%$ of farmers stated that they had lost income (mean loss $11 \%$ ) through an environmental

494 factor such as crop pests, drought, typhoon winds and flooding. Overall, farmers identify the

495 start of ecological degradation (Figure 5d) with the early 2000s (Phase IV HRS with grain), as

496 opposed to the mid-2000s or before 2000. A higher proportion of the plain's farmers give the

497 early 2000s as the starting date compared to mountain farmers.

\section{Plans for the future}

500 Around $50 \%$ of farmers state that urbanisation is a major factor limiting future agricultural

501 development and rural incomes (Figure 5e). The next ranked factor is the cost of fertilizer and

502 pesticides while other factors relate to global food prices, ecological degradation, the role of

503 government and insufficient land. Higher proportions of mountain farmers identified

504 urbanisation, the role of government and insufficient land as major limiting factors, while

505 higher proportions of farmers on the plain identified the costs of fertilizer and pesticides and

506 ecological degradation. Regarding future intentions, farmers are fairly evenly split (Figure 5f)

507 between planning to rent out the land, giving the land to family or others, and having no 
strong plans or even abandoning the farm. Mountain farmers are less certain while farmers on

509 the plain are more likely to consider renting out their land.

\section{Discussion}

“China's transition to sustainability should take advantage of its ability to implement massive

programs that can infiltrate every aspect of society rapidly” (Liu, 2010 p. 50)

Over the 65 year-long period, farmers and the environment have responded directly and indirectly to the general trend of liberalisation, a trajectory buoyed by rising population,

518 demands and incomes. The generally rising trends in provisioning services (Figure 5) reflect

519 the farmers' increased profit motivation and steadily rising personal wealth that allows for 520 improvements in the use of hybrid crops, mechanisation, fertilizer and pesticides: a process of 521 'land use intensification'. In contrast, there are parallel long-term losses or degradation of 522 some regulating services, notably soil stability, air quality and water quality (Figure 4). These 523 divergent trends constitute a long-term trade-off for food and income against environmental 524 quality; a socially and politically acceptable trade-off that has strengthened each decade since 525 the 1980s.

527 In terms of FESP, the strongest links within the social-ecological system (Figure 2) have been 528 processes operating in the States component, specifically the Adaptation by farmers to 529 successive national policy Response decisions aimed at liberalisation, increasing the Service 530 Provision of agricultural goods through intensification. This has driven investment in 531 technologies and fertilizers, and subsequent incomes, which has created a positive feedback 532 loop. As the positive loop has strengthened, the Impacts on Service Provision have been 
533 positive for provisioning services and largely negative for regulating services. However,

534 there remains a disconnect by government of the link between Impacts on all Services

535 Provision and States through Response policies that Adapt to Trade-offs and Valuation of

536 Services. Even though there is clear evidence for Trade-offs between provisioning and

537 regulating service provision, the Responses in terms of national policy have largely been

538 through Mitigation effects on economic Drivers and land use Pressures than through Adaption

539 in terms of direct environmental protection. For example, the Phase IV 'HRS with grain'

540 marketization policy period saw a shift away from grain cropping with a sharp drop in total

541 grain yield as farmers chose cash crops over grains. This is reflected in a slowing down in

542 water quality degradation and possibly some recovery in biodiversity and soil erosion (Figure

543 4) temporarily suspending the trade-off, but only as an indirect result of policy Responses

544 affecting economic Drivers. The change in policy Response during the following Phase V

545 'HRS with subsidy' period (Figure 3), when grain crops were 'made' more profitable to

546 counter declining crop yields, shows the direct link between Impacts on Service Provision,

547 Valuation of Services and Responses. Within two years, fertilizer usage and grain yields

548 renewed their long-term rise and, as a result, water quality degradation accelerated and there

549 is some evidence for declining levels of soil stability and terrestrial biodiversity (Figure 4).

550 As the subsidy system became established, the levels of county GDP per capita grew at an

551 unprecedented rate. The evidence suggests that during these phases the government and

552 farmers responded rapidly to each other's decision-making rather than the State of the

553 environment.

555 In terms of the effects of Drivers and Pressures on the States, the strongest direct evidence is

556 in terms of the short-term, rather than long-term impacts of weather events on crop yields.

557 But overall, the strongest effects of Responses on exogenous Drivers and Pressures has been 
558 through national economic growth, and especially urbanisation within rural areas, that will

559 have strengthened the Shucheng farming system through increasing market demand for crops

560 and providing additional sources of family income. Farmers have acted primarily as

561 Ecosystem Service Providers and do not appear to have influenced, or been strongly

562 influenced by, national policy Responses_that directly address Impacts on regulating services.

563 This despite the widely held views of farmers that environmental protection and restoration

564 are the government's responsibility.

566 The question now is whether the nature of the trade-off is changing to one where continued

567 and successful exploitation of provisioning services is directly undermined by a decline in

568 regulating (and supporting) services. The long-term declines in soil stability and, especially,

569 in water quality reflect the gradual losses in ecological resilience, with the sharp downward

570 declines in water quality in the 1970s and at the end of the 'HRS with grain policy' period

571 indicative of critical transitions from one steady state to another (Zhang et al., 2015). These

572 declines could be caused by long-term positive feedback loops, such as adding artificial

573 fertilizers to gain year-on-year productivity gains while natural soil fertility (encompassing

574 organic matter, soil structure and soil depth) continually deteriorates from over-cultivation.

575 However, there is no direct evidence that the trade-offs over several decades significantly

576 constrained provisioning services (although the shift in downstream lake water quality will

577 likely impact lake fisheries). For example, the fluctuating and low grain yields between 1989-

5782004 seem to be less the result of biophysical constraints and more the combined effects of

579 inefficient grain production before subsidies were introduced, and extreme climate impacts.

580 Only the last two years of grain yields (2010 and 2011) that show the first downturn since

5812001 could indicate a long-term cumulative and negative impact on crop productivity: the

582 corollary to the environmentalist's paradox (Raudsepp-Hearne et al., 2010). 
584 Even if ecological degradation is currently insufficient to reduce crop productivity, there is strong evidence that the state of soil, fluvial and lake systems in Shucheng may be shifting (or in the case of lakes have already shifted) to undesirable states (Zhang et al., 2015). The majority of farmers questioned were aware of the changes in provisioning and regulating services shown in this study, at least since Phase III. They identified water quality as the most

589 degraded regulating service, especially those living on the plain, and to some extent soil 590 quality, with fertilizers and pesticides as the main causes of degradation. Interestingly, 591 changes in the local climate were also identified, especially from the mountain farmers whose 592 livelihoods are sensitive to drought and rivers drying up, which is consistent with the PCA 593 evidence for associations with precipitation in the 1980s (Figure 5) and records of extreme 594 climate events impacting on crop production and soil stability, especially since the 1990s when mean temperatures began to rise (Figure 3). Less consistent with the biophysical records are the farmers' perceptions of when the ecological degradation began, which they generally identify as the period since the mid-2000s. This period includes a sharp decline in

598 water quality but significantly underestimates the long-term declines in water quality, air 599 quality and soil stability that started around the time the HRS was introduced in the 1980s 600 (Figure 4).

601

602 What are the implications for designing and implementing new policies over the next five to 603 thirty years? In order to address the losses of regulating services, farming has to become 604 more efficient with respect to the use of soil, water, pesticides and fertilizers. Successful 605 Land Circulation could bring more mechanisation of manual processes, leading to more 606 efficient delivery of seed, fertilizer and pesticide, and importantly produce rental incomes for 607 absent farmers. However, as observed elsewhere in China (Du \& Bo, 2011; Chen \& Du, 
2014), Shucheng farmers are uncertain about what should happen to their farms with $35 \%$

609 having no strong plans. Even on the plains only $45 \%$ of farmers are considering the Land

610 Circulation option and, in the mountains, where field sizes are mainly constrained by

611 topography, farmers are even less keen. It follows that urgent delivery of scientific and place-

612 based practical advice and guidance directly to farmers is crucial to the success of any current

613 or future land management policy (Cui et al., 2018). This all points strongly to a need for a

614 significantly improved system of information and technology transfer, probably involving a

615 more efficient coordination between agencies. Agriculture Technology Extension Centres

616 exist but many of the personnel are not qualified to give up-to-date advice (Zhang Weijian

617 personal communication) and increasingly focus on farm organisation issues and sales. In

618 selected counties, the Science and Technology Backyard programme (Zhang et al., 2016) that

619 promotes agricultural scientists living in villages among farmers shows encouraging results

620 with respect fertilizer management, irrigation and crop yields. But generally, there is a major

621 gap between making policy Responses at the national level and implementing the appropriate

622 practices for Adaptation at the local level.

624 The Opening-Up Reforms in the late 1970s set Chinese agriculture on a path that has tracked

625 the national rising level of wealth: a path-dependent union between agricultural

626 intensification, poverty alleviation and ecological degradation. Where Shucheng differs from

627 the average county is in the overall lower income levels that are partly due to the marginal

628 nature of farmland in the mountains. Nevertheless, our study is perhaps representative of the

629 hundreds of agricultural communities in marginal landscapes across China, supporting

630 millions of people, but which lag behind the general economic growth. These communities

631 may not engage in the most intensive agriculture but a long history of poor practices may still

632 jeopardise the long-term sustainability of ecosystem services in these areas. The urban lure of 
633 higher incomes is possibly stronger than in wealthier communities making the viability of

634 land tenure reforms, the transfer of information and technology, and succession of the family

635 farm far less certain as young people reject farming as a livelihood. As the current farmers

636 retire over the next 10-15 years, the issue of low farm incomes is likely to become pivotal in

637 any debate about sustainable agriculture in China.

638

\section{Conclusions}

640 - Shucheng represents a policy-responsive farming community that has driven up levels of

641 crop productivity. This has led to long-term ecological degradation, a situation viewed (in

642 2012) as an acceptable trade-off. Individual bottom-up actions framed by top-down

643 national policy and embedded in contemporary agricultural culture have led to continuing

644 losses of regulating services that reduce the resilience of the agricultural system and

645 threaten to undermine crop yields in the future. Neither the farmers nor the state has

646 directly determined the trade-off. It is more an emergent feature of farmers adapting to a

647 long-term policy of liberalisation playing out over multi-decadal timescales.

- In general, farmers have been highly responsive to policies that drive positive feedback

650 loops by developing and exploiting provisioning services according to levels of profits

651 and subsidies that, in turn, raise incomes. The periods of 'HRS with grain' and 'HRS with

652 subsidy' demonstrate the negative and positive effects of policy on farmers, as shown by

653 fluctuating crop yields. The relationship between poverty alleviation and ecosystem

654 services has been coupled strongly through provisioning services and less through

655 regulating services. Indeed, the liberalisation process that has led farmers to improve

656 agricultural productivity and their own wellbeing has not led to a stronger sense of

657 stewardship over the environment. 
- Farmers identify correctly the main types of long-term ecological degradation and the proximate causes. But they perceive the start of the degradation significantly later than the scientific evidence. The results show that the extent of degradation is only realised after rapid declines: otherwise masked by the process of 'creeping normalcy'. Water quality has deteriorated most rapidly and there is evidence that critical thresholds may have been passed in downstream lake ecosystems. Extreme climate events can deliver direct impacts on both provisioning and regulating services and there is evidence that the long-term warming trend may also have an impact on services. The long-term rates of decline in regulating services are unsustainable but in the absence of relevant policy farmers show little motivation to make restorative actions.

- Unfortunately, urbanisation, low farm incomes, low educational attainment levels and an aging demographic still represent barriers to viable farming. Incomes from farm produce and government subsidies are still low, and insufficient to maintain a farming family whose head is normally middle-aged or close to retirement. Together with the lack of information transfer and technology, today's farmers are not in a strong position to make changes that would simultaneously produce step-changes in income and reverse the negative ecological trends. Land Circulation, designed to overcome inefficient farm sizes, may not be taken up widely.

- The similarities between the long-term trends observed at Shucheng and other rural counties in eastern China (e.g. Zhang et al., 2015) indicate that the findings may apply more broadly. This indicates that maintaining or increasing current productivity levels while simultaneously slowing or reversing the losses of regulating services nationally requires new national or regional policies that promote bottom-up, restorative influences 
on the environment and a sense of stewardship within an inter-generational strategy for farm land use and management. Future national policies need to embrace systems perspectives and focus on delivering scientific and place-based information and technology to farmers through environmental advisors.

688

689 Acknowledgements

690 The work was supported by National Key Research and Development Program of China 691 (\#2017YFA0605200), Later analyses were supported by the project 'Ecology and poverty:

692 developing a new evolutionary approach' funded with support from the Ecosystem Services

693 for Poverty Alleviation Programme (ESPA) under Grant NE/I002960/1. The UK ESPA

694 programme is funded by the Department for International Development (DFID), the

695 Economic and Social Research Council (ESRC) and the Natural Environment Research

696 Council (NERC). The final manuscript was produced while JAD was in receipt of a Visiting

697 Professorship for Senior International Scientists from the Chinese Academy of Sciences held

698 at the Nanjing Institute of Geography and Limnology. We thank students from Wuhu

699 University, Wang Rong, Xue Min and Tan Lirong for help with fieldwork, and Zhang

700 Weijian for discussions. Data are available from the corresponding author.

701

702 Declaration of interest statement

703 None of the authors has any relevant interests to disclose.

704

705

706

707

708

709 


\section{References}

711 Armstrong McKay, D.I., Dearing, J.A., Dyke, J.G., Poppy, G.M. \& Firbank, L. (2019). To 712 what extent has sustainable intensification in England been achieved? Science of the Total 713 Environment, 648, 1560-1569.

Brown, L. (2013). Aquifer depletion. [online] URL

716 http://www.eoearth.org/view/article/150159/ accessed 27/06/19

Chen, J. \& Du, X. (2014). Protection of farmers' interests in rural Land Circulation of China: theoretical frame and realization mechanism. Cross-Cultural Communication, 10, 15-24.

Chen, X., Cui, Z., Fan, M., Vitousek, P., Zhao, M., Ma, W., ... Zhang F. (2014). Producing more grain with lower environmental costs. Nature, 514, 486-489. County. Hefei: Huangshan Bookstore (in Chinese).

Cui, Z., Zhang, H., Chen, X., Zhang, C., Ma, W., Huang, C., ...Dou, Z. (2018). Pursuing sustainable productivity with millions of smallholder farmers. doi:10.1038/nature25785.

Dai, X., Yu, L., Dearing, J.A., Zhang, W., Shi, Y., Zhang, F., ... Foster, G.C. (2009). The

731 recent history of hydro-geomorphic processes in the upper Hangbu river system, Anhui

732 Province, China. Geomorphology, 106, 363-375. 
734 Darnhofer, I., Fairweather, J. \& Moller, H. (2011). Assessing a farm's sustainability: insights

735 from resilience thinking. International Journal of Agricultural Sustainability, 186, 198.

736

737 Dearing, J.A., Bullock, S., Costanza, R., Dawson, T.P., Edwards, M.E., Poppy, G.M. \&

738 Smith, G. (2012b). Navigating the Perfect Storm: research strategies for social-ecological

739 systems in a rapidly evolving world. Environmental Management, 49, 767-775.

740

741 Dearing, J. A., Yang, X., Dong, X., Zhang, E., Chen, X., Langdon, P.G., ... Dawson, T.P.

742 (2012a). Extending the timescale and range of ecosystem services through

743 paleoenvironmental analyses: the example of the lower Yangtze basin. Proceedings of the

744 National Academy of Sciences, 109, E1111-1120.

745

746 Duong, T.T., Brewer, T., Luck, J., \& Zander, K. (2019) A global review of farmers'

747 perceptions of agricultural risks and risk management strategies. Agriculture, 9,

$748 \quad$ 10. doi.org/10.3390/agriculture9010010

750 Du, Y. \& Sun, B. (2011). The development of Chinese agricultural land transfer

751 system:transaction, concentration and commercialization. Journal of Agricultural Science, 3, $752 \quad 269-274$.

753

754 Foley, J. A., Ramankutty, N., Brauman, K.A., Cassidy, E.S., Gerber, J.S., Johnston, M., 755 ...Zaks, D.P.M. (2011). Solutions for a cultivated planet. Nature, 478, 337-342. 
757 Fairweather,_J. R. \& Hunt, L.M. (2009). Can farmers map their farm system? Causal mapping 758 and the sustainability of sheep/beef farms in New Zealand. Agricultural Human Values, 28, $759 \quad 55-66$.

760

761 Garnett, T., Appleby, M.C., Balmford, A., Bateman, I.J., Benton, T.G., Bloomer, P., ...

762 Godfray, H.C.J. (2013). Sustainable intensification in agriculture: premises and policies.

763 Science, 341, 33-34.

764

765 Guo, J. H., Liu, X.J., Zhang, Y., Shen, J.L., Han, W.X., Zhang, W.F., ...Zhang, F.S. (2010).

766 Significant acidification in major Chinese croplands. Science, 327, 1008-1010.

767

768 Li, C. (2010). Countermeasures and investigation of Land Circulation in less developed 769 agricultural area of Henan Province, China. Asian Agricultural Research 2: 61-64.

770

771 Li, Y., Zhang, W., Ma, L., Wu, L., Shen, J., Davies, W.J., ... Dou, Z. (2013). An analysis of

772 China's grain production: looking back and looking forward. Food and Energy Security, 3, $773 \quad 19-32$.

774

Lin Q., Zhang, K., Shen, J. \& Liu, E.F. (2019). Integrating long-term dynamics of ecosystem

services into restoration and management of large shallow lakes. Science of the Total

$777 \quad$ Environment,671, 66-75.

778

779

Liu, J. (2010). China's road to sustainability. Science, 328, 50.

780 
Liu, J., Kuang, W., Zhang, Z., Xu, X., Qin, Y., Ning, J., ... Chi, W. (2014). Spatiotemporal

782 characteristics, patterns, and causes of land-use changes in China since the late 1980s. Journal of Geographical Science, 24, 195-210.

784

Liu, J. G. \& Diamond, J. (2005). China's environment in a globalizing world. Nature, 435,

$786 \quad 1179-1186$.

787

788

789

790

791

792

793

794

795

796

Mehrabi, Z., \& Ramankutty, N. (2019). Synchronized failure of global crop production.

Nature Ecology \& Evolution. doi:10.1038/s41559-019-0862-x.

Poppy, G.M., Chiotha, S., Eigenbrod, F., Harvey, C.A., Monzák, M., Hudson,

M.D., ...Dawson, T.P. (2014). Understanding food security in a perfect storm: an ecosystem services approach. Philosophical Transactions of the Royal Society Series B 369, 20120288

[online] URL http://dx.doi.org/10.1098/rstb.2012.0288.

Pretty, J., Benton, T.G., Pervez Bharucha, Z., Dicks, L.V., Butler Flora, C., Godfray, H.C.J., ...Wratten, S. (2018). Global assessment of agricultural system redesign for sustainable intensification. Nature Sustainability 1, 441-446.

\section{$\underline{\text { R Core Team (2017). R: A language and environment for \#\# statistical computing. } \mathrm{R}}$}

Foundation for Statistical Computing, Vienna, Austria. URL https://www.R-project.org/

Raudsepp-Hearne, C., Peterson, G.D., Tengö, M., Bennett, E.M., Holland, T., Benessaiah, K., ...Pfeifer, L. (2010). Untangling the environmentalist's paradox: why is human well-being increasing as ecosystem services degrade? Bioscience, 60, 576-589. 
807 Ray, D.K., Ramankutty, N., Mueller, N.D., West, P.C. \& Foley, J.A. (2012). Recent

808 patterns of crop yield growth and stagnation. Nature Communications, 3,1293.

809

810 Rounsevell, M.D.A., Dawson, T.P. \& Harrison, P.A. (2010). A conceptual framework to

811 analyse the effects of environmental change on ecosystem services. Biodiversity and

812 Conservation, 19, 2823-2842.

813

814 Scheffer, M., Carpenter, S.R., Lenton, T.M., Bascompte, J., Brock, W., Dakos, V.,

815 ...Vandermeer, J. (2012). Anticipating critical transitions. Science, 338, 344-348.

816

817 Yan Z., Gu, H., Dai, Y., Wu, X., Dearing, J.A., Zhang, Z. \& Yu, L. (2009). Population, land 818 use and environmental impacts in Shucheng County, Anhui Province, China during the Ming 819 and Qing dynasties. Environment and History, 15, 61-78.

820

821 Yu, P. (2011). Stage achievement investigation and benefit evaluation of Return Cultivated

822 Land to Forest - to Nangang Town, Shucheng County as an example. Anhui Agricultural 823 Science Bulletin, 17, 218-221 (in Chinese).

824

825 Yuan, W.P., Li, X.L., Liang, S.L., Cui, X.F., Dong, W.J., Liu, S.G., ...Zhu, W.Q. (2014).

826 Characterization of locations and extents of afforestation from the Grain for Green Project in

827 China. Remote Sensing Letters, 5, 221-229.

828

829 Zhang, B., Zhuang, J., Zhang, J. \& Wang, R. (2010). Evaluation of the function of

830 reforestation on soil loss control in the Dabie Mountains, China. Bioinformatics and 
831 Biomedical Engineering (iCBBE), $4^{\text {th }}$ International Conference, Chengdu, China. URL

832 https://ieeexplore.ieee.org/xpl/mostRecentIssue.jsp?punumber=5513048 accessed 27/6/19

834 Zhang K., Dearing, J.A., Dawson, T.P., Dong, X., Yang, X. \& Zhang, W. (2015). Poverty

835 alleviation strategies in eastern China lead to critical ecological dynamics, Science of the

836 Total Environment, 506-507,164-181.

837

838 Zhang, K., Dearing, J.A., Tong, S.L. \& Hughes, T.P. 2016. China's degraded environment

839 enters a new normal. Trends in Ecology and Evolution 31, 175-177.

840

841 Zhang, W., Cao, G., Li, X., Zhang, H., Wang, C., Liu, Q., ...Dou, Z. (2016). Closing yield

842 gaps in China by empowering smallholder farmers. Nature 537, 671-674.

843

844 Zhang, W., Gowdy, J., Bassi, A.M., Santamaria, M., DeClerck, F., Adegboyega, A., ...

845 Wood, S.L.R. (2018). Systems thinking: an approach for understanding 'eco-agri-food

846 systems'. In TEEB for Agriculture \& Food: Scientific and Economic Foundations. Geneva:

847 UN Environment.

848

849 Zhang W., Ricketts, T.H., Kremen, C., Carney, K. \& Swinton, S.M. (2007). Ecosystem

850 services and dis-services to agriculture. Ecological Economics, 64, 253-260.

851

852 Xu, Z., Zhang, W. \& Li, M. (2014). China's grain production: a decade of consecutive

853 growth or stagnation? [online] URL http://monthlyreview.org/2014/05/01/chinas-grain-

854 production/\#en4 accessed 27/6/19 
858

859 


\section{$860 \quad$ Appendix}

\section{Questionnaire survey}

\section{Farmer Characteristics:}

1. How long have you lived on and farmed this land?

2. How old are you?

3. What is your education level?

4. How many people are supported by (or are dependent on) this farm?

5. What relation are these people to you? (e.g. spouse, children (adult or child), other family, workers, other)

6. Do you own, rent or manage this land? (please specify)

7. How much land does this farm cover?

8. What is the land currently used for? Please give land-use type and approximate area (e.g. crops (please specify), grass/hay, trees, for livestock, fallow, industry, other)?

$$
\text { Land use type }
$$

9. What farm equipment do you have access to? (include those you can rent)

10. Do you sell crops/livestock/timber and their products for profit?

a. If so, who do you sell to (e.g. neighbours, local market, co-op, commercial buying agent, food processing, etc.)?

11. Do you and your household have any non-agricultural income generating activities? If so:

a. What are these?

b. About how many hours a week do you (or other members of your household) spend on these activities?

c. Does this income contribute significantly to that from the farm?

\section{Land-Use Change:}

12. Have you changed the land use of any part of your farm, or bought/sold land, in the last 10 years?

13. If so, what did the land use change from and to?

14. Why did you make this change? (please tick all that apply)
$\square \quad$ To make more money
$\square \quad$ To minimise risk
$\square \quad$ Previous land-use became uneconomic
$\square \quad$ Changes in yield or productivity of land
$\square \quad$ Changes in water availability/ climate/weather
$\square$ Lack of labour, time or other resources please state
$\square \quad$ Took an opportunity to try new
Changes in subsidies or market prices
crop/technology/enterprise
$\square \quad$ Incentives or initiatives from local/nationa
$\square \quad$ My neighbours tried this government or EU
$\square \quad$ Suggested by family or friends
$\square \quad$ To maintain or improve the quality of the land
$\square \quad$ Other, please specify

15. What will happen to this farm when you retire?

Environmental issues:

16. Which part of environment do you think is degrading most seriously? ( )

A. Forests B. Air pollution C. Water quality D. Flooding E. Drought F. Soil erosion

G. Soil quality H. Biodiversity loss I. Others (please specify)

18. What do you think has caused the degradation? ( )

A. Fertilizer usage B. Climate change C. Deforestation D. Land use change

E. Industrialization F. Others (please specify)

19. When do you think the degradation started? ( )

$\begin{array}{lllll}\text { A. } 5 \text { years ago } & \text { B. } 10 \text { years ago } & \text { C. } 20 \text { years ago } & \text { D. } 30 \text { years ago }\end{array}$

20. Did natural disasters or other environmental problems cause you to lose money last year? If yes, 
What are the reasons ( ), and how much do you lost ( ), and what is the percentage it accounting for your total annual income? ( )

21. Which part of natural environment is more important to you, please rank them from 1 to 5,1 represent less important and 5 represent most important.

Soil erosion ( ) Water pollution ( ) Biodiversity loss ( ) Air pollution ( )

22. Where do your agricultural skills come from? ( )

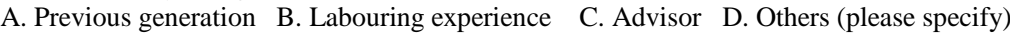

23. Do you have idle land? If yes, why? (

\section{)}

A. Land quality degradation B. Lack of labour C. Agricultural price is too low

D. too far from home E. Others (please specify)

24. What kind of subsidies did you receive last year, and how much were they worth?

25. What factor do you think limits the agricultural development and rural income in this area? ( )

A. Environment degradation B. Urbanization C. Policy D. Global food price E. Others (please specify)

\begin{tabular}{|c|c|c|c|c|}
\hline $\begin{array}{l}\text { 26. To what extent do you agree or disagree with the } \\
\text { following statements: }\end{array}$ & $\begin{array}{l}\text { Strongly } \\
\text { Agree }\end{array}$ & Agree & Disagree & $\begin{array}{l}\text { Strongly } \\
\text { Disagree }\end{array}$ \\
\hline \multicolumn{5}{|l|}{ I change the land use frequently } \\
\hline \multicolumn{5}{|l|}{ I want to maximise my profit } \\
\hline \multicolumn{5}{|l|}{ I want to minimise risk } \\
\hline \multicolumn{5}{|l|}{ I would like this farm to stay in the family } \\
\hline \multicolumn{5}{|l|}{ I want to maintain traditional farming methods } \\
\hline \multicolumn{5}{|l|}{$\begin{array}{l}\text { I am concerned that new people moving into the area will ruin its } \\
\text { character }\end{array}$} \\
\hline \multicolumn{5}{|l|}{ I watch what my neighbours are doing with their land } \\
\hline \multicolumn{5}{|l|}{$\begin{array}{l}\text { If I see my neighbours are doing well with a new farm method or } \\
\text { activity, I would try it too }\end{array}$} \\
\hline \multicolumn{5}{|l|}{ I would like to try out new agricultural methods and activities } \\
\hline \multicolumn{5}{|l|}{$\begin{array}{l}\text { I am not interested in new ideas and schemes, e.g. organic } \\
\text { farming, agricultural environmental management, precision } \\
\text { farming }\end{array}$} \\
\hline \multicolumn{5}{|l|}{$\begin{array}{l}\text { I feel that I lack the knowledge to try new farming methods and } \\
\text { activities }\end{array}$} \\
\hline \multicolumn{5}{|l|}{ I would like to research new farming methods and activities } \\
\hline \multicolumn{5}{|l|}{$\begin{array}{l}\text { I believe that I can get the resources to try new farming methods } \\
\text { and activities }\end{array}$} \\
\hline \multicolumn{5}{|l|}{$\begin{array}{l}\text { I am prepared to invest time and money in new farm equipment, } \\
\text { methods or crops }\end{array}$} \\
\hline \multicolumn{5}{|l|}{$\begin{array}{l}\text { I am interested in national agricultural policies and subsidies and } \\
\text { how they apply to my farm }\end{array}$} \\
\hline \multicolumn{5}{|l|}{ I keep track of market prices } \\
\hline \multicolumn{5}{|l|}{ I will change my land use if market prices change significantly } \\
\hline \multicolumn{5}{|l|}{ I try to anticipate changes in the market } \\
\hline \multicolumn{5}{|l|}{$\begin{array}{l}\text { I am not interested in agricultural policies and subsidies and how } \\
\text { they apply to my farm }\end{array}$} \\
\hline \multicolumn{5}{|l|}{$\begin{array}{l}\text { I think that government offers opportunities for improving farm } \\
\text { profits in this area }\end{array}$} \\
\hline I will change land use if physical farming conditions change & & & & \\
\hline
\end{tabular}

Please use this space for any information you didn't have space for earlier.

\section{Figures}

\section{Figure captions}

Figure 1. Shucheng County, lake Chaohu and the surveyed towns in the Chaohu catchment (inset shows location in eastern China). 
Figure 2. A Framework for Ecosystem Service Provision based on a modified DriverPressure-State- Impact-Response framework (Rounsevell et al., 2009).

Figure 3. Drivers, Pressures and Impacts on Shucheng county 1950-2010: a) Total population, GDP/capita and population working in agriculture (\%); b) annual mean temperature $\left({ }^{\circ} \mathrm{C}\right)$, annual precipitation $(\mathrm{mm})$ and climate-related disasters measured as 'disaster area' $\left(\mathrm{km}^{2}\right)$; c) cultivated land area $\left(\mathrm{km}^{2}\right)$, tea garden area $\left(\mathrm{km}^{2}\right)$, and Anhui fertilizer usage $\left(10^{5} \mathrm{t}\right)$.

Figure 4. States of ecosystem services in Shucheng county 1950-2010: a) normalised provisioning services - total grain yield, pigs, fruit, tea, aquatic products, and timber; b) normalised soil stability and sediment regulation regulating services - sediment magnetic susceptibility, sediment accumulation rates and $\mathrm{Rb} / \mathrm{Sr}$ geochemical ratio; $\mathrm{c}$ ) normalised air quality regulating services - sediment $\mathrm{Pb}$ and soot concentrations; d) normalised water quality regulating services - diatom-inferred total phosphorus (DI-TP) and sediment total organic carbon (TOC) - with monitoring records $\left(\mathrm{mg} \mathrm{L}^{-1}\right)$ of total phosphorus (TP), total nitrogen (TN) and chemical oxygen demand (COD); e) normalised biodiversity - rarefaction index of terrestrial pollen taxa. Vertical dashed lines delineate agricultural policy Phases I-V where HRS abbreviates Household Responsibility System (Table 1) and grey vertical bars show Great Leap Forward and Cultural Revolution.

Figure 5. Biplot of the Principal Component Analysis of the Shucheng data from 1959-2006 showing the first (PC1; 58\% of the variance) and second (PC2; 12\% of the variance) principal components for each year and the variables within the correlation circle. Three clusters can be clearly delineated, representing a) the Great Leap Forward and the early 1960s 
(red), b) the Cultural Revolution and the early Household Responsibility System (green), and c) the Household Responsibility System and market liberalisation (blue). The variables are labelled as: Pop.Tot. (Total Population), Pop.Rur. (Rural Population), Tmp. (Temperature), Prcp. (Precipitation), Tmp.Hei. (Temperature in Heifi), Prcp.Hei. (Precipitation in Heifi), TeaGard (Tea Garden Area), Fert.Anh. (Fertiliser Usage in Anhui), Cultv. (Cultivated Area), Yield.t (Total Grain Yield), Yield.kgha (Grain Yield per hectare), Pigs, Fruit, Tea, Aquatic (Aquatic Products), Timber, Biodiv (Biodiversity), SoilStab.Xfd (Soil Stability by Xfd), SoilStab.RbSr (Soil Stability by Rb/Sr), Sed Reg (Sediment Regulation by MAR), Air (Air Quality by Lead), Soot (Air Quality by Soot), DITP (Water Quality from DI-TP), TOC, Sed (Sediment Quality).

Figure 6. Farmers' questionnaire responses: a) crops grown; b) main types of ecological degradation; c) causes of ecological degradation; d) start date of ecological degradation; e) barriers or threats to farming; f) personal plans for the future. Data plotted with highest 'total' responses to the left, where 'total' data refers to responses by all farmers $(n=68)$, and 'plains' and 'mountains' refer to subsets of respondents farming the lowlands $(n=35)$ and $(n=33)$ hilly lands respectively. Percentage data in a), b), c) and f) do not add to $100 \%$ because farmers were free to choose more than one answer. 


\section{Who determines the trade-offs between agricultural production and 2 environmental quality? An evolutionary perspective from rural eastern 3 China. Household Responsibility System in 1980, the start of liberalisation, there has been a trade-off

11 between rising levels of provisioning services and falling levels of regulating services in the environment, with some evidence that critical thresholds have been passed for water quality. Using a Framework for Ecosystem Service Provision, we argue that farmers have acted only as ecosystem service providers and have not influenced the national/regional policies that have brought about the trade-offs. Over the whole period, ecological degradation is best described as an example of 'creeping normalcy' where cumulative conventional actions by individual farmers produce unsustainable losses in regulating services. The Chinese government should be acting to balance the various ecosystem services through valuation and national policy. In this respect, there is a need for a new coordination of agencies that can deliver scientific and place-based advice to farmers that will allow them to maintain productivity levels while pursuing restorative actions. Even with new policies, the draw of urban employment and high production costs threaten the viability of farming in these marginal agricultural areas, especially over the next 10-15 years when most current farmers

24 will retire.

Keywords: China; social-ecological systems, ecosystem services; evolutionary frameworks; trade-offs. 


\section{Introduction}

Warnings about the possible long term negative consequences of unsustainable farm practises (Raudsepp-Hearne et al., 2010) are partly borne out by global figures that show widespread stagnation and declines in grain yields (Mehrabi et al., 2019; Ray et al., 2012). However, the whole process through which agriculture is deemed to lie on a sustainable trajectory or not is complex. Sustainable agriculture depends not only on current top-down government policy and resource management strategies (Foley et al., 2011) but also on bottom-up decisions made by farmers in the light of national policy, markets and their knowledge about the environment (Duong et al., 2019; Fairweather et al., 2008). Farmers make decisions in response to less predictable short-term factors (Darnhofer et al., 2011), such as extreme climate events and energy costs, as well as to the likely impact of longer term trends, such as the emphasis in many countries on increasing crop yields through agricultural intensification (Garnett et al., 2013; Poppy et al., 2014; Pretty et al., 2018). In these ways, agriculture may be viewed as a complex system of ecosystem services with exogenous and endogenous drivers and pressures working through feedback mechanisms over a variety of timescales (Armstrong McKay et al., 201뭉 Zhang et al., 2018).

In the People's Republic of China, agricultural output in the period 1950-2015 rose five-fold (Li et al., 2013). This has been achieved through technological advances, including new high yielding crops, mechanisation, fertilizers, pesticides and irrigation. In addition, policy reforms have moved farming away from collective systems towards more independent commercial regimes. Government policies since 1979 mainly reflect two sets of concern: maintaining or increasing crop yields, particularly grains, and reducing the incidence of hazards, like flooding and soil erosion. In ecosystem service terms, these different 
motivations have focused on extracting provisioning goods and services, and on protecting regulating services respectively. However, despite efforts to protect the environment, the growth in production has been linked to widespread ecological degradation, particularly soil erosion, salinisation, desertification and water pollution (Liu \& Diamond, 2005).

Our recent studies have highlighted the long-term trade-off between growing provisioning services and declining regulating services within the lower Yangtze basin (Dearing et al., 2012a; Lin et al., 2019; Zhang et al., 2015), and the widespread irreversibility of environmental degradation across China (Zhang et al., 2016). Indeed, a major challenge for Chinese agriculture is to find ways of maintaining or growing outputs while stabilising or reducing the ecological impacts. Chen \& Du (2014) suggest that the socio-economic constraints could be reduced with economic development and changes in land tenure and land management. But to do this requires more detailed information about how past policies and reforms have affected the social-ecological systems in rural China.

Here we focus on one of those areas in the lower Yangtze basin, Shucheng County (hereafter Shucheng) in order to try and understand how trade-offs between rising production and deteriorating environmental quality have reflected the interaction of national agricultural policy and local farming decisions. Shucheng is an agriculturally marginal 'poverty-stricken' county with low levels of income, offering a chance to observe the environmental constraints on long term economic growth and poverty alleviation, and the possible negative consequences of environmental degradation. We have designed a research methodology that addresses the following overarching questions:

7 How have national policies affected farming decisions and ecosystem services through 
time?

- Were local farmers able to perceive the environmental degradation and make restorative actions?

- Given the findings, what are the implications for designing or implementing appropriate policies over the next thirty years?

Materials and Methods

88

\section{Shucheng County}

Shucheng (area $2092 \mathrm{~km}^{2}$ ) lies to the west of Chaohu lake in Anhui Province (Figure 1). The landscape of the county comprises the Dabie Mountains (52\% area) in the west, a central hilly area (20\% area), and alluvial plains (28\% area) extending to the lake edge. The population of the county doubled between 1950 and 2000, from 489500 to 983379 (Chorography Compilation Committee of Shucheng County, 1995; Yan et al., 2009), and is currently 1 million with $86 \%$ engaged in agriculture. As a result of reforestation since the 1960 s, the total area under cultivation decreased from $507 \mathrm{~km}^{2}$ (1950) to $416 \mathrm{~km}^{2}$ (2009). The Green for Grain Programme (1999-2007) gave payments across China for ecosystem services in order to convert croplands on steep slopes to forest (Liu et al., 2014). Main crops are rice, wheat, cotton and rapeseed in the plains with rice, tea and chestnuts in the mountains, and vegetables near major towns. Labelled by the national government as one of the $\sim 590$ 'poverty-stricken' counties of China, an annual farmer's income was (in 2008) approximately US\$ 900. Despite reforestation of up to 65\% of the steep slopes in Shucheng (Yuan et al., 2014; Yu, 2011; 
Zhang et al., 2010), soil erosion, river sedimentation, flooding and water pollution have at

104 various times become serious problems (Dai et al., 2009), undermining poverty reduction 105 activities and sustainable rural development.

\section{Chinese agricultural policy 1949-2011}

108 Since 1949, farmers in Shucheng, as in every Chinese county, have worked under the direct

109 influence of national agricultural policy. Li et al. (2013) define six historical phases of

110 national agricultural policy aimed at influencing grain production. From Phase I (1949-1977)

111 to Phase VI (2011 onwards) there was a shift of direct control and responsibility from the

112 government to the household. Phase I was a collectivised economy where farmers were given 113 quotas for food production but no extra compensation for producing beyond the quota. The

114 introduction of the Household Responsibility System (HRS) at the beginning of Phase II in

1151978 reallocated land rights from the People's collectives to individual farms with the

116 opportunity for farmers to sell surplus produce at a market price. During Phase II, farmers'

117 quotas were reduced which gave further incentives to produce crops for sale at market prices.

118 Phase III extended the liberalisation process with promotion of pesticides and fertilizers and

119 non-grain cash crops through price controls. Phase IV (1999-2003) saw a drop in national

120 grain production as farmers shifted their focus towards cash crops in response to the

121 government leaving grain prices to be controlled by the market. In order to restore grain

122 production, in 2004, the government removed agricultural tax and introduced subsidies for

123 grain production (Phase V). Although national figures for grain production have been revived

124 by these measures the rates of increase since then (Phase VI) are low relative to the large

125 inputs of fertilizer and other resources ( $\mathrm{Li}$ et al., 2013). The ongoing response to 'inefficient

126 farming' is the reform of land management through Land Circulation (Li, 2010) involving

127 aggregation of small fields into larger units that is designed to improve the economies of scale 
and incomes.

130 Some national fluctuations in historical grain production figures are therefore explained by

131 changes in national policy (Xu et al., 2014). However, since 2000, there have been notable

132 short- term fluctuations in annual yields that have led to speculation that agricultural

133 production in some regions is now biophysically constrained by resource depletion, such as

134 groundwater (Brown, 2013) or positive feedback mechanisms, like soil acidification (e.g. Guo

135 et al., 2010). Other commentators (e.g. Li et al., 2013) argue that the slow increase in grain

136 production in recent years is due to the lack of modern agricultural technology and methods.

137 Indeed, results from field experiments across China (Chen et al., 2014) suggest that current

138 yields of rice, wheat and maize could be raised by $18-35 \%$ through the adoption of integrated

139 soil-crop system management practices though the results of a major field campaign trial puts

140 these figures at a lower level, $\underline{\text { at }}$ about $11 \%$ (Cui et al., 2018).

\section{Study approach}

143 We take an evolutionary approach (Dearing et al., 2012b) that combines information on

144 changes in national policy, farm activities and ecosystem processes over 65 years together

145 with the views of current farmers. An evolutionary perspective is important for identifying the

146 timescales of drivers, ecosystem states and human responses, understanding the nature of

147 trade-offs between ecosystem services, and evaluating the extent to which a social-ecological

148 system is contingent on past events and conditions, or even path-dependent. Such

149 information can also help identify whether detrimental transitions (tipping points) in, for

150 example, productivity or ecological states, have already occurred or inform on the likelihood

151 of thresholds being transgressed in the near future. Transitions are often relatively rapid but

152 may be the culmination of slow incremental change in some key process that are 
153 imperceptible without long term ecological monitoring (Zhang et al., 2007; Zhang et al. 2015),

154 and may be costly to fix or even irreversible (Scheffer et al., 2012). In order to facilitate

155 analyses, we embed the evolutionary approach within a Framework for Ecosystem Service

156 Provision (FESP - Rounsevell et al., 2009) based on a modified Driver-Pressure-State-Impact-

157 Response $^{1}$ (DPSIR) framework (Figure 1). The FESP integrates across multiple services and

158 scales, makes explicit the exogeneous and endogenous drivers within the system, and,

159 importantly, allows for feedback mechanisms that drive non-linear interactions.

160

161 Annual statistics for agriculture, population, economy and climate are available at provincial

162 (1949-2008) and county levels ( 1980s to 2008) giving time-series for provisioning

163 ecosystem services and socio-economic-environmental drivers, but ecological monitoring of

164 water quality and other ecological processes are, at best, available for recent years only.

165 Regulating services are the most important in terms of determining the sustainability of land

166 systems but are often poorly understood or under-represented in studies because of

167 insufficient data. Therefore, we use laboratory analyses of lake sediments to allow the novel

168 historical reconstruction of multi-decadal trends in major regulating ecological services within

169 the upstream catchment and lake (Dearing et al., 2012a). Here, we use dated sediment cores

170 sampled from Chaohu lake as proxies for decadal time-series of water quality, lake

171 productivity, air quality, sediment quality, terrestrial biodiversity and soil stability.

172

173 We first describe the multi-decadal trends and use principal component analysis (PCA) and

174 breakpoint analyses to reveal plausible long-term associations between Drivers, Pressures,

175 States and Impacts (Figure 2). Second, we compare the temporal data against shorter term

176 policy changes to tease out plausible links between Responses (policy decisions), Pressures,

\footnotetext{
${ }^{1}$ Throughout the text we capitalize the first letter of terms referenced within the FESP.
} 
177 Impacts and States. Third, we interrogate the links between human behaviour and ecosystem

178 services within States and Impacts through the results of a questionnaire survey, exploring

179 how changes in ecosystem services are perceived by local farmers, how they currently assess

180 their farming in terms of policy and income, and how they are planning for the future.

181 Finally, we draw the findings together in addressing the research questions.

182

183 Time-series data and statistical analyses

184 Official annual statistical data for social, economic and agricultural changes were obtained for

185 Shucheng, Anhui Province, and an average for of all China's Provinces from Statistical Year

186 Books. Climate data were obtained from monitoring records in the nearby Hefei City located

$18750 \mathrm{~km}$ to the northeast of Shucheng (Figure 1). Sediment data were obtained (see Dearing et

188 al. 2012a for full details) from sediment cores taken from the western side of Chaohu with a

189 piston corer in 2006. Core sediments were subsampled at a $0.5 \mathrm{~cm}$ resolution for $0-50 \mathrm{~cm}$ and

$1901 \mathrm{~cm}$ resolution in deeper sediments. Sediment samples were dated using ${ }^{210} \mathrm{~Pb}$ and ${ }^{137} \mathrm{Cs}$

191 radioisotopes, and a constant rate of supply model was used to calculate a chronology and

192 depth-age curves for each core. Only data in the period 1950-2006 are used in the present

193 study. Typically, the dating errors are \pm 5 years (2 st. dev) for 1950 reducing to \pm 2 years in

194 recent years. The sediments were analysed to produce the following proxies for ecosystem

195 services:

196 - Sediment regulation proxy: dry mass sediment accumulation rates (SAR)

197 - Soil stability proxies: magnetic susceptibility and the $\mathrm{Sr} / \mathrm{Rb}$ geochemical ratio.

198 - Air quality proxies: lead $(\mathrm{Pb})$ and soot concentrations.

199 Water quality proxies: diatom inferred-total phosphorus and total organic carbon

$200 \quad$ (TOC).

201 - Biodiversity proxy: rarefaction indices for floristic richness in pollen counts. 
202 Normalised data varying between 0 and 1 are used (Figure 3) so that trends can be easily

203 compared and aggregated. The formula used for scaling the data series $(\mathrm{x} 1: \mathrm{xn})$ to $(0: 1)$ is $\mathrm{x} 1$ -

$204(\min x 1: x n) /[(\max x 1: x n)-(\min x 1: x n)]$ where $\min$ and $\max$ are minimum and maximum

205 values within the data range. In the case of biodiversity, values of 1 and 0 equate to highest

206 and lowest levels of ecosystem service. For all other proxy records, like soil stability, values

207 in the range 1 to 0 were inverted so that values of 1 and 0 equate to highest and lowest levels

208 of ecosystem service respectively. Principal components analysis of the time-series data was

209 performed and plotted by the prcomp and ggbiplot functions in R (

210 Statistically significant $(\mathrm{p} \leq 0.01)$ breakpoints in time-series were calculated (Zhang et al.,

2112015 ) as evidence for shifts in system or sub-system states.

212

213 Questionnaires and focus groups

214 A questionnaire with closed and open questions was designed (see Appendix) to obtain

215 information about current farming activities, farmer's perceptions of ecological degradation

216 and their future plans. Farmers were selected randomly from towns situated in the two most

217 contrasting landscape-farm systems across the county (Figure 2): mountains (Hepeng) and

218 plains (Hangbu). The survey, conducted in August 2012, was administered to 68 farmers (33

219 from Hepeng and 35 from Hangbu). Trained university research students conducted face-to-

220 face interviews with farmers at their house or at local agricultural offices, where interviews

221 typically lasted 30 minutes. All the interviews were conducted on a voluntary basis, and

222 farmers consented verbally to a written set of survey aims and the anonymous use of the 223 collected data.

225 Results

226 Trends and statistical analyses 
Trends for the main Drivers, Pressures and Impacts within the system show (Figure 3) rising trends for population from 1949, GDP/capita from the 1990s (when records began), fertilizer applications from 1990 (when records began), and mean annual temperature from the 1980s. In contrast, the proportion of the rural population has steadily declined since the 1980s, as has the area of cultivated land that declined rapidly in the 1960s and again in the 2000s.

The multi-decadal data for States of ecosystem services (Figure 4) clearly show two sets of broad trends. Provisioning services show generally increasing trends over the whole period starting in 1950 (grain, pigs, tea) or from the 1990s (fruit, aquatic products and timber). In contrast, regulating services show generally decreasing trends, particularly from the 1970s (soil stability-Rb/Sr ratio, air quality, water quality) and 1990s (terrestrial biodiversity) onwards. The period 1950-1980 shows stable or even improving (terrestrial biodiversity) regulating services (Figure 4).

PCA for the dataset (Figure 5) shows PC1 accounting for $\sim 58 \%$ of the explained variance

242 controlled by cultivated land area opposing many of the other records, especially crop yield, 243 population, air quality $(\underline{\mathrm{Pb}})$, soot, tea, soil instability, fertilizers, total lake water phosphorus,

244 fruit and pigs. PC2, with $\sim 12 \%$ variance, shows temperature opposing precipitation, soil 245 instability (X-1 $\%$ ) and biodiversity. PCA analyses identify three clusters representing the 246 periods 1959-1968, 1969-1993 and 1994-2006 which map onto the Great Leap Forward and 247 the 1960s, the Cultural Revolution and early HRS period, and the later period of HRS with 248 rural market liberation and onwards (Table 1). These three periods shift from initial 249 associations with high levels of cultivated land and relatively low yields, to associations with 250 climate, soil erosion and biodiversity, to the most recent associations with relatively high 251 yields and poor air and water quality. An alternative analysis, for the 1952-2011 dataset, gives 
252 PC1 with $67.7 \%$ of the explained variance with cultivated land area opposing yield,

253 population, pigs and yield (kg/ha). PC2 with $\sim 11.3 \%$ explained variance shows temperature,

254 timber, aquatics and fruit opposing precipitation. The pattern of samples shows three broad

255 time periods dominated by 1952-1968, 1969-1996 and 1997-2011. For 1991-2011, PC1 with

$25651.4 \%$ of the explained variance shows cultivated land area opposing total population,

257 temperature, aquatic, fruit, GDP and yield ( $\mathrm{kg} / \mathrm{ha})$. PC2 with $\sim 18.6 \%$ explained variance

258 shows rural population opposing pigs and precipitation. The pattern of samples shows three

259 broad time periods dominated by 1991-1998, 1999-2006 and 2007-2011 which more or less

260 map onto the later period of HRS with rural market liberation, HRS grain policy and HRS

261 subsidy policy.

262

263 Results of the breakpoint analysis for all the time-series identify (Zhang et al., 2015) abrupt

264 changes in lake water quality in 1979 and in aggregated regulating services in 1977 broadly at

265 the time of the early HRS. Breakpoints in provisioning service series are less clear but there

266 is evidence for shifts during three periods: the Cultural Revolution in the mid-1960s to the

267 early 1970s, the HRS of the late 1970s to early 1980s, and the HRS with rural market

268 liberation in the mid-1990s.

269

270 Overall, the visual and statistical analyses of broad trends provide the following insights:

271 - Long term rises in provisioning services contrast with long term declines in several

272 indicators of regulating services;

273 - The analyses describe a 'land use intensification' process involving greater provisioning

274 of agricultural and aquatic products from a reducing farmland area involving a smaller

275 proportion of the population, and environmental degradation through losses of soil, air and

276 water regulating services; 
- Together, these findings point to a long-term trade-off between successful agricultural production driven largely by improved farm technologies, and environmental

279 deterioration;

- Successful agricultural production has been associated with rising total populations and 281 total incomes (GDP/capita) even as the proportion of the rural population declines;

- Losses of ecological resilience and transgression of thresholds in natural ecosystems

283 reached their peak during the 1970s;

- Statistically, the social-ecological system has evolved through three states seemingly determined by major national policy Responses associated with the Great Leap Forward, the Cultural Revolution and early HRS, and the later HRS with market liberation.

- The 'early HRS' and the later 'HRS with market liberation' periods are linked to abrupt changes in regulating and provisioning services that may indicate the transgression of thresholds.

\section{Policy and social-ecological change}

This section focuses on the shorter-term associations between national policy Responses and local changes in social-ecological States and Impacts. Organised by the first five phases of policy, it refers to key dates and trends (Figures 3 and 4) described in section 3.

Phase I Government control (1949-1977)

297 The early period of direct government control (Table 1) is notable for two major political 298 initiatives that affected farmers: the Great Leap Forward (1958-1961) and the Cultural 299 Revolution (1966-1976). The beginning of the Cultural Revolution maps on to the boundary

300 between two PCA clusters in the late 1960s suggesting that the Cultural Revolution represented a major shift in the Response-Pressure-State connections within a single phase of 
national policy. In Shucheng, the rise in rural population after 1949 plateaued after 1955 and

303 fell to a temporary minimum during the Great Leap Forward. This period is associated with

304 the highest recorded cultivated land area, reduced terrestrial biodiversity and loss of soil

305 stability (in two out of the three proxies) as the steeper marginal slopes were opened up. This

306 is consistent with documented deforestation before the 1970s in the upper Hangbu (Dai et al.,

307 2009) where forest area declined from $60 \%$ in the early 1950 s to $27 \%$ in the mid-1970s and

308 was associated with high levels of soil erosion. From 1964, the rural population rose again

309 with increasing production of grains, aquatic products, tea and pigs; changes that create the

310 first statistically significant shift in provisioning services. The following period, the Cultural

311 Revolution, saw declining cultivated areas, recovering levels of terrestrial biodiversity, rising

312 pig and aquatic production and seemingly increased soil stability. However, recovery of soil

313 stability after the Great Leap Forward may be misleading because the Longhekou reservoir

314 (built in 1958) will have trapped much of the sediment from the upper catchment. The

315 reservoir sediment records show highest values for surface soil erosion in the mid to late

316 1970s (Dai et al., 2009) that coincide with the end of a seven-year period (1970-1977) in

317 which there was a 4-fold increase in the area under tea plantations. Tea plantations are often

318 situated on steep slopes to aid drainage, maintained with no ground cover, and liable to severe

319 rilling. The move to increase tea plantations suggests that some land use diversification and

320 farm income generation was occurring at the start of the Cultural Revolution before the

321 introduction of the HRS, effectively creating a new social-ecological State. The impact of

322 Phase I policies on farming and ecosystem services was therefore varied. It occurred largely

323 through the direct encouragement of early deforestation of marginal mountain slopes to raise

324 crop production but ultimately led to the expansion of tea plantations. To what extent the tea

325 expansion was nationally directed or locally determined is not known. 
328 The introduction of the HRS in 1978 (Table 1) is associated (Figure 3 and 4) with a constant 329 cultivated land area, and rising tea, fruit and pig production; changes reflected in the second 330 statistical shift in provisioning services. The steady rise in grain production since 1965 slows 331 during Phase II with a significant drop in 1980 that coincides with a peak in the measurement 332 of 'disaster area', possibly reflecting the lagged effect of the major drought in 1978. More

333 certainly, the start of the period is marked by statistical shifts in water and air quality 334 suggesting that the deforestation in Phase I coupled to the start of rural industrialisation and 335 agricultural intensification using artificial fertilizers in Phase II had major detrimental 336 environmental impacts. Terrestrial biodiversity fluctuates around the levels seen in the later 337 part of Phase I but soil stability ( $\mathrm{Rb} / \mathrm{Sr}$ ratio) decreases further suggesting soil erosion had 338 extended from the mountains above the reservoir to other parts of the county. Two phases of check dam building in the late 1980s (and later in Phase III) support the records for soil

340 stability and sediment regulation services (sediment accumulation rates) that show a major 341 decline through the late 1970s and 1980s as a result of continued accelerated erosion, despite 342 reforestation schemes in 1976 and 1980. But overall, if Phase I was a period when policies 343 destabilised soils and destroyed biodiversity, it seems that Phase II was the turning point 344 towards destabilisation of air and water quality.

Phase III HRS with rural market liberalisation policy (1985-1998)

347 The period of 'HRS with rural market liberalisation' (Table 1) in Shucheng prior to 1997 is

348 associated with a constant rural population and slowly increasing wealth, before a sharp 349 increase in county GDP per capita in 1997-1998 as the rural population declines. Grain 350 production also rises steadily from 1985 until a major decline in 1991, which is followed by a 351 recovery and a return to just below former levels in 1998. Pig production rises steadily until 
the end of the period, aquatic and timber production both show sharp rises in the 1990s, but

353 tea and fruit production show overall declines. These contrasting patterns of crop production

354 are matched by large fluctuations in fertilizer usage. Interestingly, major statistical shifts in

355 both provisioning services and the whole social-ecological State (Figure 5 and section 3)

356 occur during the mid-1990s, suggesting a major change in Response-States connections

357 within Phase III. Whatever the drivers of these changes, the ecological responses are equally

358 diverse. One record for water quality (total organic carbon) shows rapid deterioration from the

359 start of Phase III, but the other record (diatom-inferred total phosphorus) fluctuates about

360 previous levels. One record for soil stability $(\mathrm{Rb} / \mathrm{Sr}$ ratio) steadily declines through this

361 period whereas the other record (magnetic susceptibility) fluctuates significantly in the period

362 around 1990. There is strong evidence that some of the patterns in crop production and in the

363 soil and water responses are climatically driven. The sharp drops in grain production and

364 major fluctuations in soil stability at this time are consistent with the effects of the extreme

365 rainfall and floods (1991-1992) and peak measurements of 'disaster areas' (1991-1995). Air

366 quality continues to deteriorate in the first half of the phase before recovering and then falling

367 back in the last years. Terrestrial biodiversity shows fluctuating values before falling rapidly

368 from a peak in 1994 that parallels the rise in timber production. Overall, Phase III is typified

369 by fluctuating patterns of crop production that may suggest a significant move towards

370 trialling different crops or farming techniques but may also reflect the impact of extreme

371 climate. Certainly, this phase sees the start of upward trends in the cash crops of timber,

372 aquatic and fruit, and a gradual contraction of the area under cultivation. These agricultural

373 changes continue to drive losses of regulating services. 
The end of Phase III is characterised by a fall in the rural population that stabilises in Phase

377 IV, the period of 'HRS with grain' policy (Table 1). Cultivated land area falls, grain

378 production fluctuates, grain productivity increases and fertilizer usage rises sharply before

379 falling indicating that more marginal land was abandoned. Meanwhile tea plantations show a

380 steady rise for the first time in $\sim 15$ years, and pig, fruit and aquatic production show

381 continuations of the rising trends that started in Phase III. This shift towards lower levels of

382 grain production as more profitable cash crops expand may explain the slow but steady

383 growth in county GDP per capita. But some of the fluctuations in the grain data may also

384 reflect the negative effects on agriculture by the major floods of 2002-03, which are marked

385 by peak values for measured 'disaster area'. Data for timber production drops during this

386 period and this may be reflected in the recovery in the records of terrestrial biodiversity.

387 Records of soil stability show evidence for a long-term recovery (in two of the three proxy

388 records) with an upturn in one of the records ( $\mathrm{Rb} / \mathrm{Sr}$ ratio). Water quality records now show

389 rapidly declining signals possibly responding to the high levels of fertilizer usage. Out of all

390 the regulating services, only air quality records show evidence for stabilised or constant

391 conditions. Overall, Phase IV describes a contracting agricultural area, shifts in the choice of

392 crop production, the highest recorded fertilizer usage and significant negative impacts on 393 water quality.

Phase V HRS with subsidy policy (2004-2011)

396 The introduction of an 'HRS with subsidy' policy in Phase V (Table 1) is associated with

397 increasing size of cultivated land area, increasing rural population, increased tea plantation

398 area, increased fertilizer usage, rising grain yields and productivity, rising aquatic and timber

399 production, but steadily declining pig production. The main impacts on regulating services

400 until 2006 (when records end) are further declines in soil stability, biodiversity and water 
quality. Water monitoring data (lake Chaohu) between 2003-2010 show relatively high but

402 fluctuating values for total nitrogen and chemical oxygen demand, but rising values for total 403 phosphorus that confirm the long term downward trajectory for water quality. Overall, Phase

404 V shows the impetus to the rural population and crop production induced by subsidies, with 405 the associated losses of soil stability and water quality services.

406

407

\section{Farmers'views}

408 This section describes the results of a farmer questionnaire analysis.

\section{Farm status}

411 The farms in the survey are small with an average area of $0.44 \pm 0.68$ ha (maximum $3.63 \mathrm{ha}$ )

412 supporting on average $3.7 \pm 2.2$ persons. Mountain farms are on average $38 \%$ smaller in area 413 than the farms on the plain. The main crops are rice, wheat, cotton, rapeseed oil crops and 414 maize (22\%) (Figure 6a) with less rice and more maize grown in the mountains. The farmers 415 are typically middle-aged to old, with a mean age of $52 \pm 15$ years and modal peak 60-64 416 years, having worked on the same farm for $23 \pm 15$ years (maximum 40 years). Around $70 \%$ 417 have been educated only to primary school level. Only $19 \%$ stated that farming was their 418 main source of income, and 93\% have family members working in the town. Non419 agricultural income (as \% of their total income) is on average $77 \% \pm 18 \%$. Current 420 government subsidies received by the farmers range from zero to 6600 Yuan/yr ( 1090 USD) 421 with an average $597 \pm 1106$ Yuan/yr ( 100 \pm 180 USD) largely determined by the farm size. 422 Subsidies to the mountain farms are on average $60 \%$ lower. 
In general, the farmers' views on agricultural management are consistent across the groups

426 from the mountains and plains. Not surprisingly, the overwhelming majority want to

427 maximise profit and minimise risk. Over $90 \%$ of farmers are interested in how national

428 agricultural policies and subsidy schemes apply to their farms, and a similar percentage keep

429 track of market prices. A majority (71\%) would like to try out new agricultural ideas, like

430 organic or precision farming, but a larger majority (90\%) think they lack the appropriate

431 knowledge. Many farmers believe that resources for new methods are unavailable to them and

432 are generally unprepared to invest time and money in new crops and equipment. It should be

433 noted that there is a tendency for these attitudes to differ between the sub-groups. Farmers on

434 the plain are the least convinced that extra resources are available but are more prepared to

435 invest their own resources. They are also less inclined to change the land use when market

436 prices change. Overall, a majority of all farmers (69\%) do not believe that the government

437 offers opportunities for improving farm profits. It seems that the largest influences on an

438 individual farmer is the success of nearby farms. More than $75 \%$ of farmers would copy a

439 neighbour's new activity if they saw that it was successful.

\section{Views on ecological degradation}

442 The farmers rank water quality, drought and soil quality as the most important types of

443 ecological degradation and losses of regulating services (Figure 6b). But there are differences

444 in the sub-groups, with mountain farmers ranking drought and rivers running dry the highest,

445 and the farmers on the plain ranking water quality and soil quality the highest. Only $8 \%$

446 stated that there was no degradation. The whole group varies in identifying the main causes

447 of degradation as chemical fertilizer and pesticide use (Figure $5 \mathrm{c}$ ), climate change, over-

448 cultivation, new crops/techniques and deforestation, with farmers on the plain emphasising

449 the importance of fertilizer and pesticides compared to the mountain farmers. Off-record 
discussions with farmers revealed a dominant view that the responsibility for the degradation

451 lies with the government, not with farmers themselves. In the year preceding the survey,

$452 \sim 60 \%$ of farmers stated that they had lost income (mean loss $11 \%$ ) through an environmental

453 factor such as crop pests, drought, typhoon winds and flooding. Overall, farmers identify the

454 start of ecological degradation (Figure 5d) with the early 2000s (Phase IV HRS with grain), as 455 opposed to the mid-2000s or before 2000. A higher proportion of the plain's farmers give the 456 early 2000s as the starting date compared to mountain farmers.

Plans for the future

459 Around $50 \%$ of farmers state that urbanisation is a major factor limiting future agricultural

460 development and rural incomes (Figure 5e). The next ranked factor is the cost of fertilizer and 461 pesticides while other factors relate to global food prices, ecological degradation, the role of government and insufficient land. Higher proportions of mountain farmers identified urbanisation, the role of government and insufficient land as major limiting factors, while higher proportions of farmers on the plain identified the costs of fertilizer and pesticides and ecological degradation. Regarding future intentions, farmers are fairly evenly split (Figure 5f) between planning to rent out the land, giving the land to family or others, and having no strong plans or even abandoning the farm. Mountain farmers are less certain while farmers on the plain are more likely to consider renting out their land.

\section{Discussion}

"China's transition to sustainability should take advantage of its ability to implement massive programs that can infiltrate every aspect of society rapidly” (Liu, 2010 p. 50) 
475 Over the 65 year-long period, farmers and the environment have responded directly and

476 indirectly to the general trend of liberalisation, a trajectory buoyed by rising population,

477 demands and incomes. The generally rising trends in provisioning services (Figure 5) reflect

478 the farmers' increased profit motivation and steadily rising personal wealth that allows for

479 improvements in the use of hybrid crops, mechanisation, fertilizer and pesticides: a process of

480 'land use intensification'. In contrast, there are parallel long-term losses or degradation of

481 some regulating services, notably soil stability, air quality and water quality (Figure 4). These

482 divergent trends constitute a long-term trade-off for food and income against environmental

483 quality; a socially and politically acceptable trade-off that has strengthened each decade since

484 the 1980s.

486 In terms of FESP, the strongest links within the social-ecological system (Figure 2) have been

487 processes operating in the States component, specifically the Adaptation by farmers to

488 successive national policy Response decisions aimed at liberalisation, increasing the Service

489 Provision of agricultural goods through intensification. This has driven investment in

490 technologies and fertilizers, and subsequent incomes, which has created a positive feedback

491 loop. As the positive loop has strengthened, the Impacts on Service Provision have been

492 positive for provisioning services and largely negative for regulating services. However,

493 there remains a disconnect by government of the link between Impacts on all Services

494 Provision and States through Response policies that Adapt to Trade-offs and Valuation of

495 Services. Even though there is clear evidence for Trade-offs between provisioning and

496 regulating service provision, the Responses in terms of national policy have largely been

497 through Mitigation effects on economic Drivers and land use Pressures than through Adaption

498 in terms of direct environmental protection. For example, the Phase IV 'HRS with grain'

499 marketization policy period saw a shift away from grain cropping with a sharp drop in total 
grain yield as farmers chose cash crops over grains. This is reflected in a slowing down in

501 water quality degradation and possibly some recovery in biodiversity and soil erosion (Figure 4) temporarily suspending the trade-off, but only as an indirect result of policy Responses

503 affecting economic Drivers. The change in policy Response during the following Phase V 'HRS with subsidy' period (Figure 3), when grain crops were 'made' more profitable to counter declining crop yields, shows the direct link between Impacts on Service Provision, Valuation of Services and Responses. Within two years, fertilizer usage and grain yields renewed their long-term rise and, as a result, water quality degradation accelerated and there is some evidence for declining levels of soil stability and terrestrial biodiversity (Figure 4). As the subsidy system became established, the levels of county GDP per capita grew at an unprecedented rate. The evidence suggests that during these phases the government and farmers responded rapidly to each other's decision-making rather than the State of the environment.

In terms of the effects of Drivers and Pressures on the States, the strongest direct evidence is in terms of the short-term, rather than long-term impacts of weather events on crop yields. But overall, the strongest effects of Responses on exogenous Drivers and Pressures has been through national economic growth, and especially urbanisation within rural areas, that will have strengthened the Shucheng farming system through increasing market demand for crops and providing additional sources of family income. Farmers have acted primarily as Ecosystem Service Providers and do not appear to have influenced, or been strongly influenced by, national policy Responses_that directly address Impacts on regulating services. This despite the widely held views of farmers that environmental protection and restoration are the government's responsibility. 
The question now is whether the nature of the trade-off is changing to one where continued

526 and successful exploitation of provisioning services is directly undermined by a decline in regulating (and supporting) services. The long-term declines in soil stability and, especially, in water quality reflect the gradual losses in ecological resilience, with the sharp downward

529 declines in water quality in the 1970s and at the end of the 'HRS with grain policy' period 530 indicative of critical transitions from one steady state to another (Zhang et al., 2015). These

531 declines could be caused by long-term positive feedback loops, such as adding artificial 532 fertilizers to gain year-on-year productivity gains while natural soil fertility (encompassing 533 organic matter, soil structure and soil depth) continually deteriorates from over-cultivation.

534 However, there is no direct evidence that the trade-offs over several decades significantly 535 constrained provisioning services (although the shift in downstream lake water quality will 536 likely impact lake fisheries). For example, the fluctuating and low grain yields between 19895372004 seem to be less the result of biophysical constraints and more the combined effects of 538 inefficient grain production before subsidies were introduced, and extreme climate impacts. 539 Only the last two years of grain yields (2010 and 2011) that show the first downturn since 5402001 could indicate a long-term cumulative and negative impact on crop productivity: the 541 corollary to the environmentalist's paradox (Raudsepp-Hearne et al., 2010).

543 Even if ecological degradation is currently insufficient to reduce crop productivity, there is

544 strong evidence that the state of soil, fluvial and lake systems in Shucheng may be shifting (or 545 in the case of lakes have already shifted) to undesirable states (Zhang et al., 2015). The 546 majority of farmers questioned were aware of the changes in provisioning and regulating 547 services shown in this study, at least since Phase III. They identified water quality as the most 548 degraded regulating service, especially those living on the plain, and to some extent soil 549 quality, with fertilizers and pesticides as the main causes of degradation. Interestingly, 
changes in the local climate were also identified, especially from the mountain farmers whose

551 livelihoods are sensitive to drought and rivers drying up, which is consistent with the PCA

552 evidence for associations with precipitation in the 1980s (Figure 5) and records of extreme

553 climate events impacting on crop production and soil stability, especially since the 1990s

554 when mean temperatures began to rise (Figure 3). Less consistent with the biophysical

555 records are the farmers' perceptions of when the ecological degradation began, which they

556 generally identify as the period since the mid-2000s. This period includes a sharp decline in

557 water quality but significantly underestimates the long-term declines in water quality, air

558 quality and soil stability that started around the time the HRS was introduced in the 1980s

559 (Figure 4).

561 What are the implications for designing and implementing new policies over the next five to

562 thirty years? In order to address the losses of regulating services, farming has to become

563 more efficient with respect to the use of soil, water, pesticides and fertilizers. Successful

564 Land Circulation could bring more mechanisation of manual processes, leading to more

565 efficient delivery of seed, fertilizer and pesticide, and importantly produce rental incomes for

566 absent farmers. However, as observed elsewhere in China (Du \& Bo, 2011; Chen \& Du,

567 2014), Shucheng farmers are uncertain about what should happen to their farms with $35 \%$

568 having no strong plans. Even on the plains only $45 \%$ of farmers are considering the Land

569 Circulation option and, in the mountains, where field sizes are mainly constrained by

570 topography, farmers are even less keen. It follows that urgent delivery of scientific and place-

571 based practical advice and guidance directly to farmers is crucial to the success of any current

572 or future land management policy (Cui et al., 2018). This all points strongly to a need for a

573 significantly improved system of information and technology transfer, probably involving a

574 more efficient coordination between agencies. Agriculture Technology Extension Centres 
575 exist but many of the personnel are not qualified to give up-to-date advice (Zhang Weijian

576 personal communication) and increasingly focus on farm organisation issues and sales. $\underline{\text { In }}$

$577 \quad$ selected counties, the Science and Technology Backyard programme (Zhang et al., 2016) that

578 promotes agricultural scientists living in villages among farmers shows encouraging results

579 with respect fertilizer management, irrigation and crop yields. But generally, there is a major

580 gap between making policy Responses at the national level and implementing the appropriate

581 practices for Adaptation at the local level.

The Opening-Up Reforms in the late 1970s set Chinese agriculture on a path that has tracked

584 the national rising level of wealth: a path-dependent union between agricultural

585 intensification, poverty alleviation and ecological degradation. Where Shucheng differs from

586 the average county is in the overall lower income levels that are partly due to the marginal

587 nature of farmland in the mountains. Nevertheless, our study is perhaps representative of the

588 hundreds of agricultural communities in marginal landscapes across China, supporting

589 millions of people, but which lag behind the general economic growth. These communities

590 may not engage in the most intensive agriculture but a long history of poor practices may still

591 jeopardise the long-term sustainability of ecosystem services in these areas. The urban lure of

592 higher incomes is possibly stronger than in wealthier communities making the viability of

593 land tenure reforms, the transfer of information and technology, and succession of the family

594 farm far less certain as young people reject farming as a livelihood. As the current farmers

595 retire over the next 10-15 years, the issue of low farm incomes is likely to become pivotal in

596 any debate about sustainable agriculture in China.

\section{Conclusions}

599 - Shucheng represents a policy-responsive farming community that has driven up levels of

600 crop productivity. This has led to long-term ecological degradation, a situation viewed (in 
601 2012) as an acceptable trade-off. Individual bottom-up actions framed by top-down

602 national policy and embedded in contemporary agricultural culture have led to continuing

603 losses of regulating services that reduce the resilience of the agricultural system and

604 threaten to undermine crop yields in the future. Neither the farmers nor the state has

605 directly determined the trade-off. It is more an emergent feature of farmers adapting to a

606 long-term policy of liberalisation playing out over multi-decadal timescales.

607

608 - In general, farmers have been highly responsive to policies that drive positive feedback

609 loops by developing and exploiting provisioning services according to levels of profits

610 and subsidies that, in turn, raise incomes. The periods of 'HRS with grain' and 'HRS with

611 subsidy' demonstrate the negative and positive effects of policy on farmers, as shown by

612 fluctuating crop yields. The relationship between poverty alleviation and ecosystem

613 services has been coupled strongly through provisioning services and less through

614 regulating services. Indeed, the liberalisation process that has led farmers to improve

615 agricultural productivity and their own wellbeing has not led to a stronger sense of

$616 \quad$ stewardship over the environment.

618 - Farmers identify correctly the main types of long-term ecological degradation and the

619 proximate causes. But they perceive the start of the degradation significantly later than

620 the scientific evidence. The results show that the extent of degradation is only realised

621 after rapid declines: otherwise masked by the process of 'creeping normalcy'. Water

622 quality has deteriorated most rapidly and there is evidence that critical thresholds may

623 have been passed in downstream lake ecosystems. Extreme climate events can deliver

624 direct impacts on both provisioning and regulating services and there is evidence that the

625 long-term warming trend may also have an impact on services. The long-term rates of 
626 decline in regulating services are unsustainable but in the absence of relevant policy

627 farmers show little motivation to make restorative actions.

629 - Unfortunately, urbanisation, low farm incomes, low educational attainment levels and an 630 aging demographic still represent barriers to viable farming. Incomes from farm produce 631 and government subsidies are still low, and insufficient to maintain a farming family 632 whose head is normally middle-aged or close to retirement. Together with the lack of 633 information transfer and technology, today's farmers are not in a strong position to make 634 changes that would simultaneously produce step-changes in income and reverse the 635 negative ecological trends. Land Circulation, designed to overcome inefficient farm sizes, 636 may not be taken up widely.

- The similarities between the long-term trends observed at Shucheng and other rural 639 counties in eastern China (e.g. Zhang et al., 2015) indicate that the findings may apply 640 more broadly. This indicates that maintaining or increasing current productivity levels while simultaneously slowing or reversing the losses of regulating services nationally requires new national or regional policies that promote bottom-up, restorative influences

643 on the environment and a sense of stewardship within an inter-generational strategy for

644 farm land use and management. Future national policies need to embrace systems

645 perspectives and focus on delivering scientific and place-based information and 646 technology to farmers through environmental advisors.

648 Declaration of interest statement

649 None of the authors has any relevant interests to disclose.

650 
652

653

654

655 


\section{References}

657 Armstrong McKay, D.I., Dearing, J.A., Dyke, J.G., Poppy, G.M. \& Firbank, L. (2019). To 658 what extent has sustainable intensification in England been achieved? Science of the Total 659 Environment, 648, 1560-1569.

661 Brown, L. (2013). Aquifer depletion. [online] URL

662 http://www.eoearth.org/view/article/150159/ accessed 27/06/19

664 Chen, J. \& Du, X. (2014). Protection of farmers' interests in rural Land Circulation of China: 665 theoretical frame and realization mechanism. Cross-Cultural Communication, 10, 15-24.

Chen, X., Cui, Z., Fan, M., Vitousek, P., Zhao, M., Ma, W., ... Zhang F. (2014). Producing more grain with lower environmental costs. Nature, 514, 486-489.

669

Chorography Compilation Committee of Shucheng County. (1995). Annals of Shucheng 671 County. Hefei: Huangshan Bookstore (in Chinese).

672

673 Cui, Z., Zhang, H., Chen, X., Zhang, C., Ma, W., Huang, C., ...Dou, Z. (2018). Pursuing 674 sustainable productivity with millions of smallholder farmers. doi:10.1038/nature25785. 675

676 Dai, X., Yu, L., Dearing, J.A., Zhang, W., Shi, Y., Zhang, F., ... Foster, G.C. (2009). The 677 recent history of hydro-geomorphic processes in the upper Hangbu river system, Anhui 678 Province, China. Geomorphology, 106, 363-375.

679 
680 Darnhofer, I., Fairweather, J. \& Moller, H. (2011). Assessing a farm's sustainability: insights

681 from resilience thinking. International Journal of Agricultural Sustainability, 186, 198.

682

683 Dearing, J.A., Bullock, S., Costanza, R., Dawson, T.P., Edwards, M.E., Poppy, G.M. \&

684 Smith, G. (2012b). Navigating the Perfect Storm: research strategies for social-ecological

685 systems in a rapidly evolving world. Environmental Management, 49, 767-775.

686

687 Dearing, J. A., Yang, X., Dong, X., Zhang, E., Chen, X., Langdon, P.G., ... Dawson, T.P.

688 (2012a). Extending the timescale and range of ecosystem services through

689 paleoenvironmental analyses: the example of the lower Yangtze basin. Proceedings of the

690 National Academy of Sciences, 109, E1111-1120.

691

692 Duong, T.T., Brewer, T., Luck, J., \& Zander, K. (2019) A global review of farmers'

693 perceptions of agricultural risks and risk management strategies. Agriculture, 9,

694 10. doi.org/10.3390/agriculture9010010

695

696 Du, Y. \& Sun, B. (2011). The development of Chinese agricultural land transfer

697 system:transaction, concentration and commercialization. Journal of Agricultural Science, 3, $698 \quad 269-274$.

699

700 Foley, J. A., Ramankutty, N., Brauman, K.A., Cassidy, E.S., Gerber, J.S., Johnston, M., 701 ...Zaks, D.P.M. (2011). Solutions for a cultivated planet. Nature, 478, 337-342. 
703 Fairweather,_J. R. \& Hunt, L.M. (2009). Can farmers map their farm system? Causal mapping 704 and the sustainability of sheep/beef farms in New Zealand. Agricultural Human Values, 28, $705 \quad 55-66$.

706

707 Garnett, T., Appleby, M.C., Balmford, A., Bateman, I.J., Benton, T.G., Bloomer, P., ...

708 Godfray, H.C.J. (2013). Sustainable intensification in agriculture: premises and policies.

709 Science, 341, 33-34.

710

711 Guo, J. H., Liu, X.J., Zhang, Y., Shen, J.L., Han, W.X., Zhang, W.F., ...Zhang, F.S. (2010).

712 Significant acidification in major Chinese croplands. Science, 327, 1008-1010.

713

714 Li, C. (2010). Countermeasures and investigation of Land Circulation in less developed 715 agricultural area of Henan Province, China. Asian Agricultural Research 2: 61-64.

716

717 Li, Y., Zhang, W., Ma, L., Wu, L., Shen, J., Davies, W.J., ... Dou, Z. (2013). An analysis of

718 China's grain production: looking back and looking forward. Food and Energy Security, 3, $719 \quad 19-32$.

721 Lin Q., Zhang, K., Shen, J. \& Liu, E.F. (2019). Integrating long-term dynamics of ecosystem

722 services into restoration and management of large shallow lakes. Science of the Total

723 Environment,671, 66-75.

Liu, J. (2010). China's road to sustainability. Science, 328, 50.

726 
Liu, J., Kuang, W., Zhang, Z., Xu, X., Qin, Y., Ning, J., ... Chi, W. (2014). Spatiotemporal

728 characteristics, patterns, and causes of land-use changes in China since the late 1980s. Journal of Geographical Science, 24, 195-210.

730

Liu, J. G. \& Diamond, J. (2005). China's environment in a globalizing world. Nature, 435,

$732 \quad 1179-1186$.

733

Mehrabi, Z., \& Ramankutty, N. (2019). Synchronized failure of global crop production.

Nature Ecology \& Evolution. doi:10.1038/s41559-019-0862-x.

Poppy, G.M., Chiotha, S., Eigenbrod, F., Harvey, C.A., Monzák, M., Hudson,

M.D., ...Dawson, T.P. (2014). Understanding food security in a perfect storm: an ecosystem services approach. Philosophical Transactions of the Royal Society Series B 369, 20120288

740 [online] URL http://dx.doi.org/10.1098/rstb.2012.0288.

742 Pretty, J., Benton, T.G., Pervez Bharucha, Z., Dicks, L.V., Butler Flora, C., Godfray,

$743 \quad$ H.C.J., ...Wratten, S. (2018). Global assessment of agricultural system redesign

744 for sustainable intensification. Nature Sustainability 1, 441-446.

$\underline{\text { R Core Team (2017). R: A language and environment for \#\# statistical computing. } \mathrm{R}}$

747 Foundation for Statistical Computing, Vienna, Austria. URL https://www.R-project.org/

749 Raudsepp-Hearne, C., Peterson, G.D., Tengö, M., Bennett, E.M., Holland, T., Benessaiah, K., 750 ...Pfeifer, L. (2010). Untangling the environmentalist's paradox: why is human well-being

751 increasing as ecosystem services degrade? Bioscience, 60, 576-589. 
753 Ray, D.K., Ramankutty, N., Mueller, N.D., West, P.C. \& Foley, J.A. (2012). Recent

754 patterns of crop yield growth and stagnation. Nature Communications, 3,1293.

755

756 Rounsevell, M.D.A., Dawson, T.P. \& Harrison, P.A. (2010). A conceptual framework to 757 analyse the effects of environmental change on ecosystem services. Biodiversity and 758 Conservation, 19, 2823-2842.

759

760 Scheffer, M., Carpenter, S.R., Lenton, T.M., Bascompte, J., Brock, W., Dakos, V., 761 ...Vandermeer, J. (2012). Anticipating critical transitions. Science, 338, 344-348.

762

763 Yan Z., Gu, H., Dai, Y., Wu, X., Dearing, J.A., Zhang, Z. \& Yu, L. (2009). Population, land 764 use and environmental impacts in Shucheng County, Anhui Province, China during the Ming 765 and Qing dynasties. Environment and History, 15, 61-78.

766

767 Yu, P. (2011). Stage achievement investigation and benefit evaluation of Return Cultivated

768 Land to Forest - to Nangang Town, Shucheng County as an example. Anhui Agricultural 769 Science Bulletin, 17, 218-221 (in Chinese).

770

771 Yuan, W.P., Li, X.L., Liang, S.L., Cui, X.F., Dong, W.J., Liu, S.G., ...Zhu, W.Q. (2014).

772 Characterization of locations and extents of afforestation from the Grain for Green Project in 773 China. Remote Sensing Letters, 5, 221-229.

774

775 Zhang, B., Zhuang, J., Zhang, J. \& Wang, R. (2010). Evaluation of the function of

776 reforestation on soil loss control in the Dabie Mountains, China. Bioinformatics and 
777 Biomedical Engineering (iCBBE), $4^{\text {th }}$ International Conference, Chengdu, China. URL

778 https://ieeexplore.ieee.org/xpl/mostRecentIssue.jsp?punumber=5513048 accessed 27/6/19

779

780 Zhang K., Dearing, J.A., Dawson, T.P., Dong, X., Yang, X. \& Zhang, W. (2015). Poverty

781 alleviation strategies in eastern China lead to critical ecological dynamics, Science of the

782 Total Environment, 506-507,164-181.

783

784 Zhang, K., Dearing, J.A., Tong, S.L. \& Hughes, T.P. 2016. China's degraded environment

785 enters a new normal. Trends in Ecology and Evolution 31, 175-177.

786

787 Zhang, W., Cao, G., Li, X., Zhang, H., Wang, C., Liu, Q., ...Dou, Z. (2016). Closing yield

788 gaps in China by empowering smallholder farmers. Nature 537, 671-674.

789

790 Zhang, W., Gowdy, J., Bassi, A.M., Santamaria, M., DeClerck, F., Adegboyega, A., ...

791 Wood, S.L.R. (2018). Systems thinking: an approach for understanding 'eco-agri-food

792 systems'. In TEEB for Agriculture \& Food: Scientific and Economic Foundations. Geneva:

793 UN Environment.

794

795 Zhang W., Ricketts, T.H., Kremen, C., Carney, K. \& Swinton, S.M. (2007). Ecosystem

796 services and dis-services to agriculture. Ecological Economics, 64, 253-260.

797

798 Xu, Z., Zhang, W. \& Li, M. (2014). China's grain production: a decade of consecutive

799 growth or stagnation? [online] URL http://monthlyreview.org/2014/05/01/chinas-grain-

800 production/\#en4 accessed 27/6/19 
802

803

804

805 


\section{Appendix}

\section{7 \\ Questionnaire survey}

\section{Farmer Characteristics:}

1. How long have you lived on and farmed this land?

2. How old are you?

3. What is your education level?

4. How many people are supported by (or are dependent on) this farm?

5. What relation are these people to you? (e.g. spouse, children (adult or child), other family, workers, other)

6. Do you own, rent or manage this land? (please specify)

7. How much land does this farm cover?

8. What is the land currently used for? Please give land-use type and approximate area (e.g. crops (please specify), grass/hay, trees, for livestock, fallow, industry, other)?

$$
\text { Land use type }
$$

9. What farm equipment do you have access to? (include those you can rent)

10. Do you sell crops/livestock/timber and their products for profit?

a. If so, who do you sell to (e.g. neighbours, local market, co-op, commercial buying agent, food processing, etc.)?

11. Do you and your household have any non-agricultural income generating activities? If so:

a. What are these?

b. About how many hours a week do you (or other members of your household) spend on these activities?

c. Does this income contribute significantly to that from the farm?

\section{Land-Use Change:}

12. Have you changed the land use of any part of your farm, or bought/sold land, in the last 10 years?

13. If so, what did the land use change from and to?

14. Why did you make this change? (please tick all that apply)
$\square \quad$ To make more money
$\square \quad$ To minimise risk
$\square \quad$ Previous land-use became uneconomic
$\square \quad$ Changes in yield or productivity of land
$\square \quad$ Changes in water availability/ climate/weather
$\square$ Lack of labour, time or other resources please
Took an opportunity to try new
state
crop/technology/enterprise
$\square \quad$ Changes in subsidies or market prices
$\square \quad$ My neighbours tried this
government or EU
$\square \quad$ Suggested by family or friends
$\square \quad$ Other, please specify

15. What will happen to this farm when you retire?

Environmental issues:

16. Which part of environment do you think is degrading most seriously? ( )

A. Forests B. Air pollution C. Water quality D. Flooding E. Drought F. Soil erosion

G. Soil quality H. Biodiversity loss I. Others (please specify)

18. What do you think has caused the degradation? ( )

A. Fertilizer usage B. Climate change C. Deforestation D. Land use change

E. Industrialization F. Others (please specify)

19. When do you think the degradation started? ( )

$\begin{array}{llll}\text { A. } 5 \text { years ago } & \text { B. } 10 \text { years ago } & \text { C. } 20 \text { years ago } & \text { D. } 30 \text { years ago }\end{array}$

20. Did natural disasters or other environmental problems cause you to lose money last year? If yes, 
What are the reasons ( ), and how much do you lost ( ), and what is the percentage it accounting for your total annual income? ( )

21. Which part of natural environment is more important to you, please rank them from 1 to 5,1 represent less important and 5 represent most important.

Soil erosion ( ) Water pollution ( ) Biodiversity loss ( ) Air pollution ( )

22. Where do your agricultural skills come from? ( )

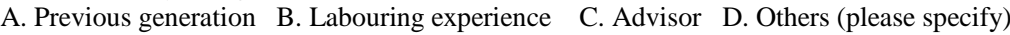

23. Do you have idle land? If yes, why? (

)

A. Land quality degradation B. Lack of labour C. Agricultural price is too low

D. too far from home E. Others (please specify)

24. What kind of subsidies did you receive last year, and how much were they worth?

25. What factor do you think limits the agricultural development and rural income in this area? ( )

A. Environment degradation B. Urbanization C. Policy D. Global food price E. Others (please specify)

\begin{tabular}{|c|c|c|c|c|}
\hline $\begin{array}{l}\text { 26. To what extent do you agree or disagree with the } \\
\text { following statements: }\end{array}$ & $\begin{array}{l}\text { Strongly } \\
\text { Agree }\end{array}$ & Agree & Disagree & $\begin{array}{l}\text { Strongly } \\
\text { Disagree }\end{array}$ \\
\hline \multicolumn{5}{|l|}{ I change the land use frequently } \\
\hline \multicolumn{5}{|l|}{ I want to maximise my profit } \\
\hline \multicolumn{5}{|l|}{ I want to minimise risk } \\
\hline \multicolumn{5}{|l|}{ I would like this farm to stay in the family } \\
\hline \multicolumn{5}{|l|}{ I want to maintain traditional farming methods } \\
\hline \multicolumn{5}{|l|}{$\begin{array}{l}\text { I am concerned that new people moving into the area will ruin its } \\
\text { character }\end{array}$} \\
\hline \multicolumn{5}{|l|}{ I watch what my neighbours are doing with their land } \\
\hline \multicolumn{5}{|l|}{$\begin{array}{l}\text { If I see my neighbours are doing well with a new farm method or } \\
\text { activity, I would try it too }\end{array}$} \\
\hline \multicolumn{5}{|l|}{ I would like to try out new agricultural methods and activities } \\
\hline \multicolumn{5}{|l|}{$\begin{array}{l}\text { I am not interested in new ideas and schemes, e.g. organic } \\
\text { farming, agricultural environmental management, precision } \\
\text { farming }\end{array}$} \\
\hline \multicolumn{5}{|l|}{$\begin{array}{l}\text { I feel that I lack the knowledge to try new farming methods and } \\
\text { activities }\end{array}$} \\
\hline \multicolumn{5}{|l|}{ I would like to research new farming methods and activities } \\
\hline \multicolumn{5}{|l|}{$\begin{array}{l}\text { I believe that I can get the resources to try new farming methods } \\
\text { and activities }\end{array}$} \\
\hline \multicolumn{5}{|l|}{$\begin{array}{l}\text { I am prepared to invest time and money in new farm equipment, } \\
\text { methods or crops }\end{array}$} \\
\hline \multicolumn{5}{|l|}{$\begin{array}{l}\text { I am interested in national agricultural policies and subsidies and } \\
\text { how they apply to my farm }\end{array}$} \\
\hline \multicolumn{5}{|l|}{ I keep track of market prices } \\
\hline \multicolumn{5}{|l|}{ I will change my land use if market prices change significantly } \\
\hline \multicolumn{5}{|l|}{ I try to anticipate changes in the market } \\
\hline \multicolumn{5}{|l|}{$\begin{array}{l}\text { I am not interested in agricultural policies and subsidies and how } \\
\text { they apply to my farm }\end{array}$} \\
\hline \multicolumn{5}{|l|}{$\begin{array}{l}\text { I think that government offers opportunities for improving farm } \\
\text { profits in this area }\end{array}$} \\
\hline I will change land use if physical farming conditions change & & & & \\
\hline
\end{tabular}

Please use this space for any information you didn't have space for earlier.

\section{Figures}

\section{Figure captions}

Figure 1. Shucheng County, lake Chaohu and the surveyed towns in the Chaohu catchment (inset shows location in eastern China). 
Figure 2. A Framework for Ecosystem Service Provision based on a modified DriverPressure-State- Impact-Response framework (Rounsevell et al., 2009).

Figure 3. Drivers, Pressures and Impacts on Shucheng county 1950-2010: a) Total population, $\mathrm{GDP} /$ capita and population working in agriculture $(\%)$; b) annual mean temperature $\left({ }^{\circ} \mathrm{C}\right)$, annual precipitation $(\mathrm{mm})$ and climate-related disasters measured as 'disaster area' $\left(\mathrm{km}^{2}\right)$; c) cultivated land area $\left(\mathrm{km}^{2}\right)$, tea garden area $\left(\mathrm{km}^{2}\right)$, and Anhui fertilizer usage $\left(10^{5} \mathrm{t}\right)$.

Figure 4. States of ecosystem services in Shucheng county 1950-2010: a) normalised provisioning services - total grain yield, pigs, fruit, tea, aquatic products, and timber; b) normalised soil stability and sediment regulation regulating services - sediment magnetic susceptibility, sediment accumulation rates and $\mathrm{Rb} / \mathrm{Sr}$ geochemical ratio; $\mathrm{c}$ ) normalised air quality regulating services - sediment $\mathrm{Pb}$ and soot concentrations; d) normalised water quality regulating services - diatom-inferred total phosphorus (DI-TP) and sediment total organic carbon (TOC) - with monitoring records $\left(\mathrm{mg} \mathrm{L}^{-1}\right)$ of total phosphorus (TP), total nitrogen (TN) and chemical oxygen demand (COD); e) normalised biodiversity - rarefaction index of terrestrial pollen taxa. Vertical dashed lines delineate agricultural policy Phases I-V where HRS abbreviates Household Responsibility System (Table 1) and grey vertical bars show Great Leap Forward and Cultural Revolution.

Figure 5. Biplot of the Principal Component Analysis of the Shucheng data from 1959-2006 showing the first (PC1; 58\% of the variance) and second (PC2; 12\% of the variance) principal components for each year and the variables within the correlation circle. Three clusters can be clearly delineated, representing a) the Great Leap Forward and the early 1960s 
(red), b) the Cultural Revolution and the early Household Responsibility System (green), and c) the Household Responsibility System and market liberalisation (blue). The variables are labelled as: Pop.Tot. (Total Population), Pop.Rur. (Rural Population), Tmp. (Temperature), Prcp. (Precipitation), Tmp.Hei. (Temperature in Heifi), Prcp.Hei. (Precipitation in Heifi), TeaGard (Tea Garden Area), Fert.Anh. (Fertiliser Usage in Anhui), Cultv. (Cultivated Area), Yield.t (Total Grain Yield), Yield.kgha (Grain Yield per hectare), Pigs, Fruit, Tea, Aquatic (Aquatic Products), Timber, Biodiv (Biodiversity), SoilStab.Xfd (Soil Stability by Xfd), SoilStab.RbSr (Soil Stability by Rb/Sr), Sed Reg (Sediment Regulation by MAR), Air (Air Quality by Lead), Soot (Air Quality by Soot), DITP (Water Quality from DI-TP), TOC, Sed (Sediment Quality).

Figure 6. Farmers' questionnaire responses: a) crops grown; b) main types of ecological degradation; c) causes of ecological degradation; d) start date of ecological degradation; e) barriers or threats to farming; f) personal plans for the future. Data plotted with highest 'total' responses to the left, where 'total' data refers to responses by all farmers $(n=68)$, and 'plains' and 'mountains' refer to subsets of respondents farming the lowlands $(n=35)$ and $(n=33)$ hilly lands respectively. Percentage data in a), b), c) and f) do not add to $100 \%$ because farmers were free to choose more than one answer. 


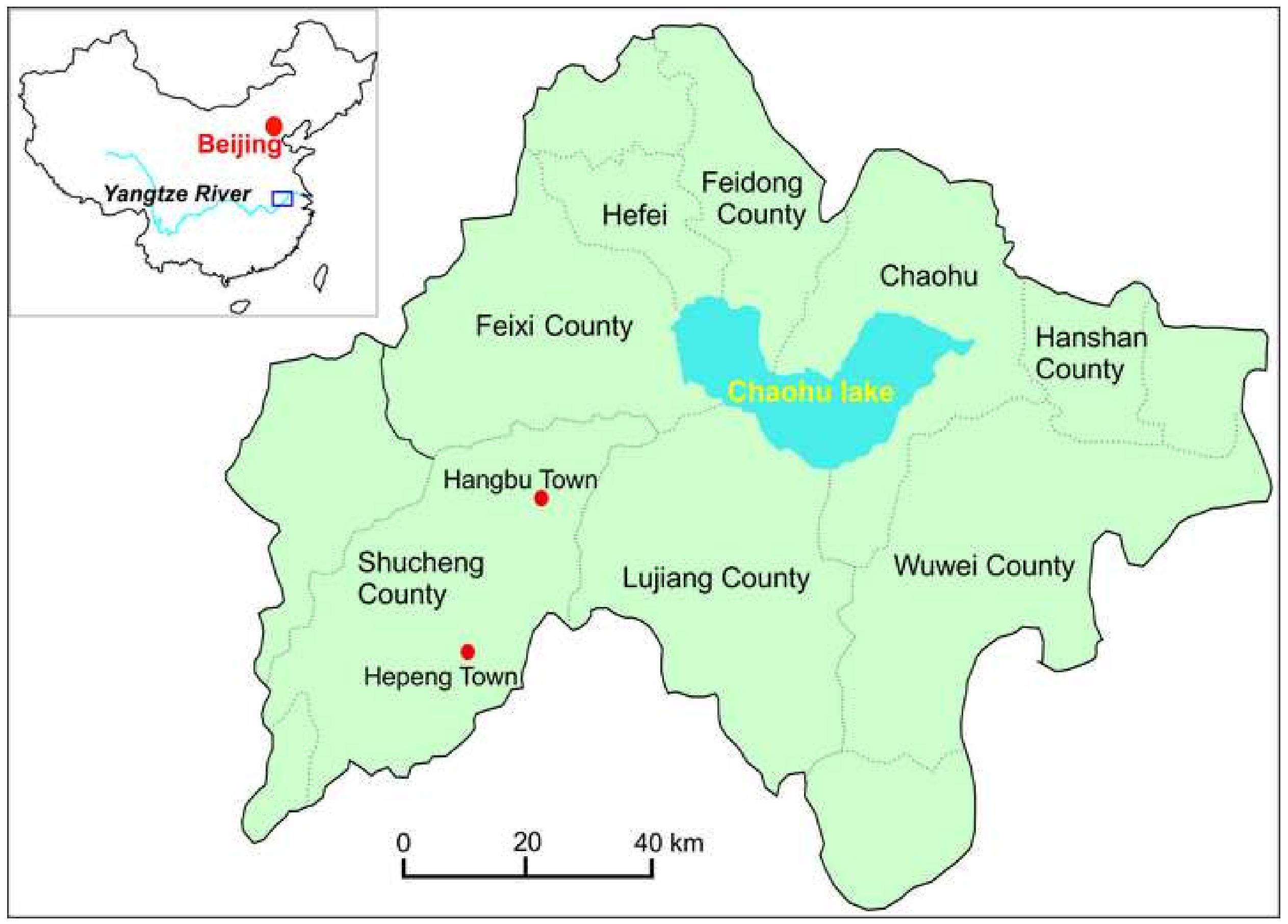


Social-ecological system

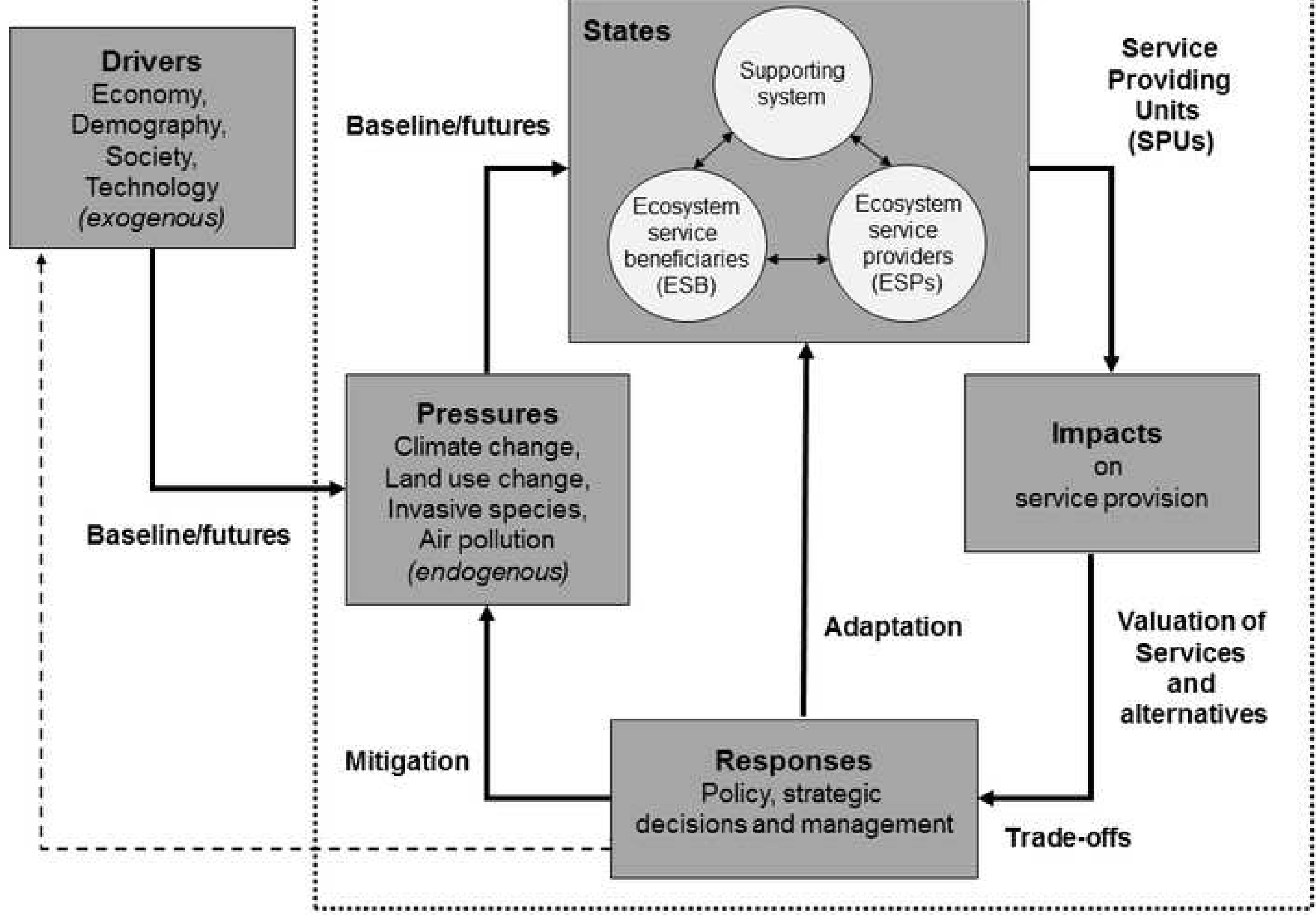



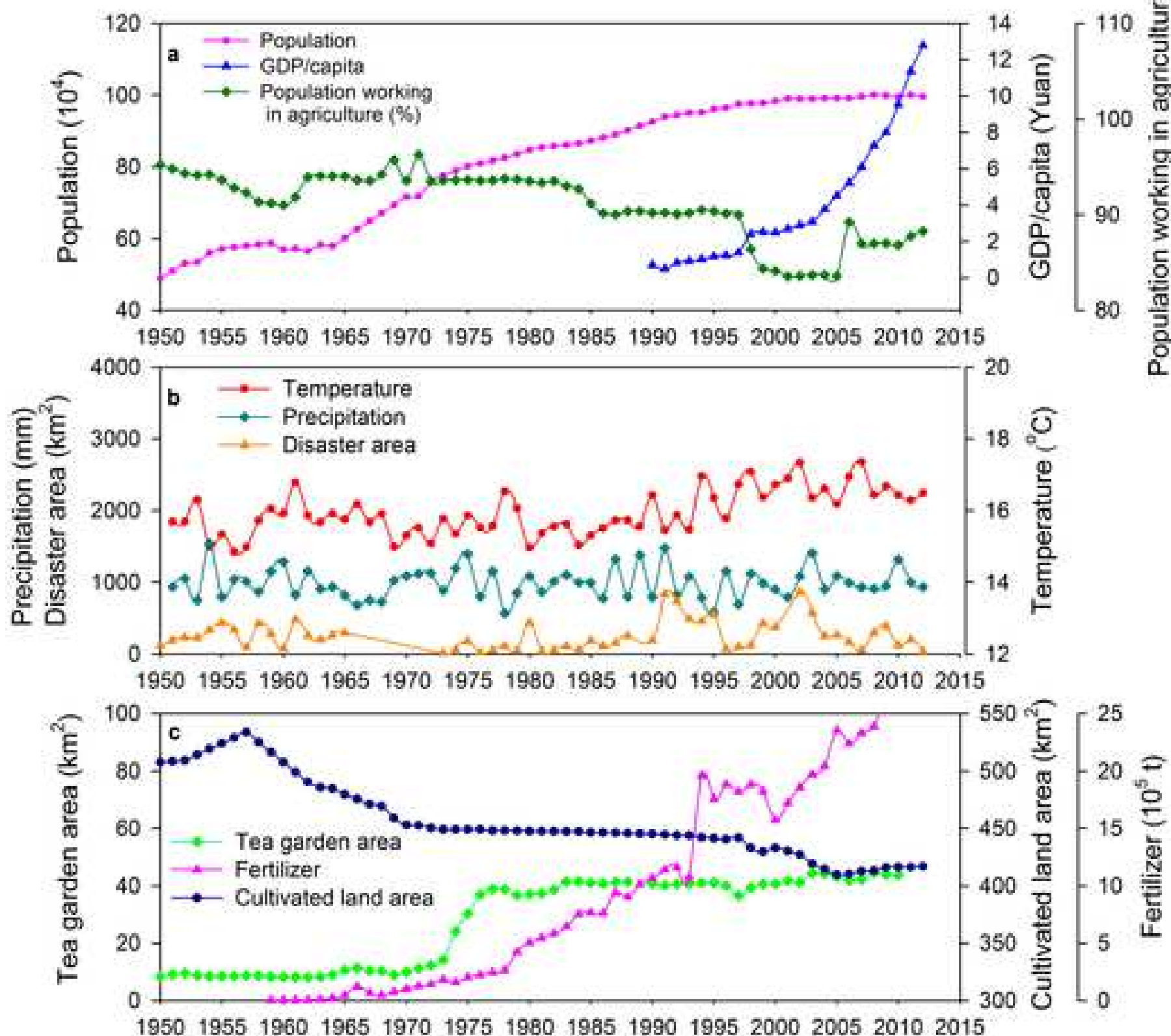

19501955196019651970197519801985199019952000200520102015 

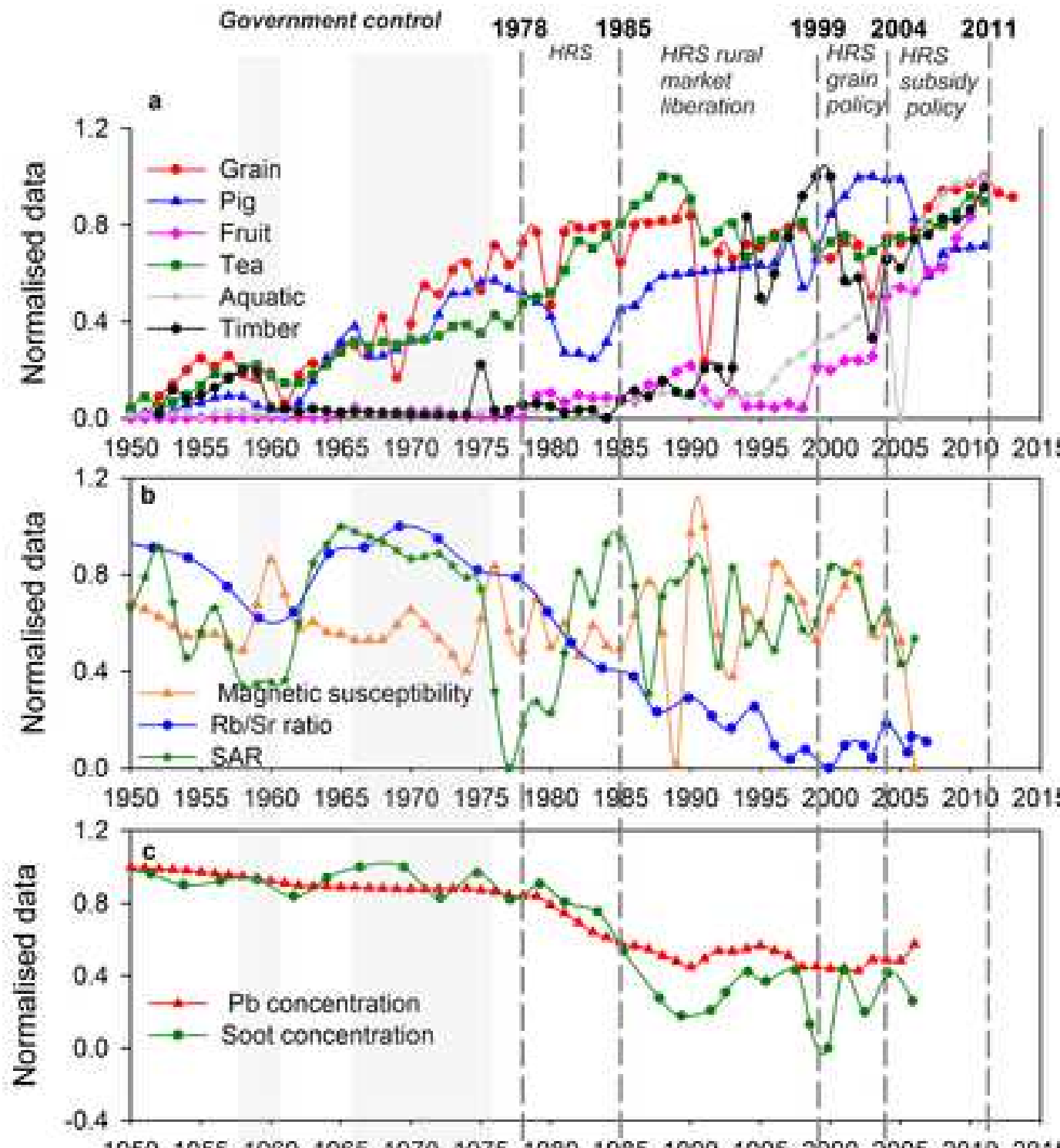

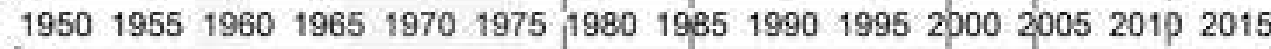
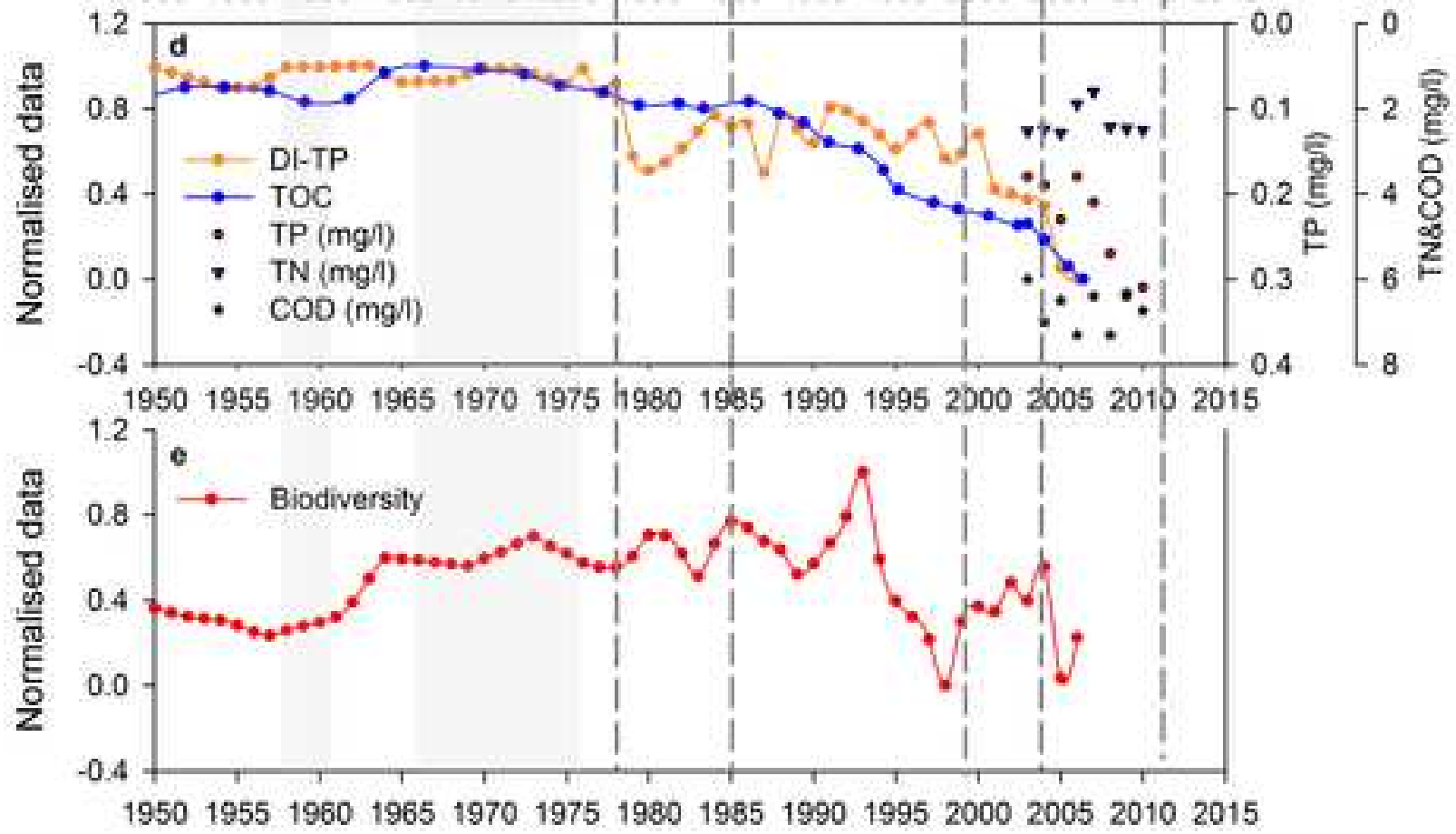
1959 A) GLF + 1960s 1969 B) CR + early HRS 1994 C) HRS + markets

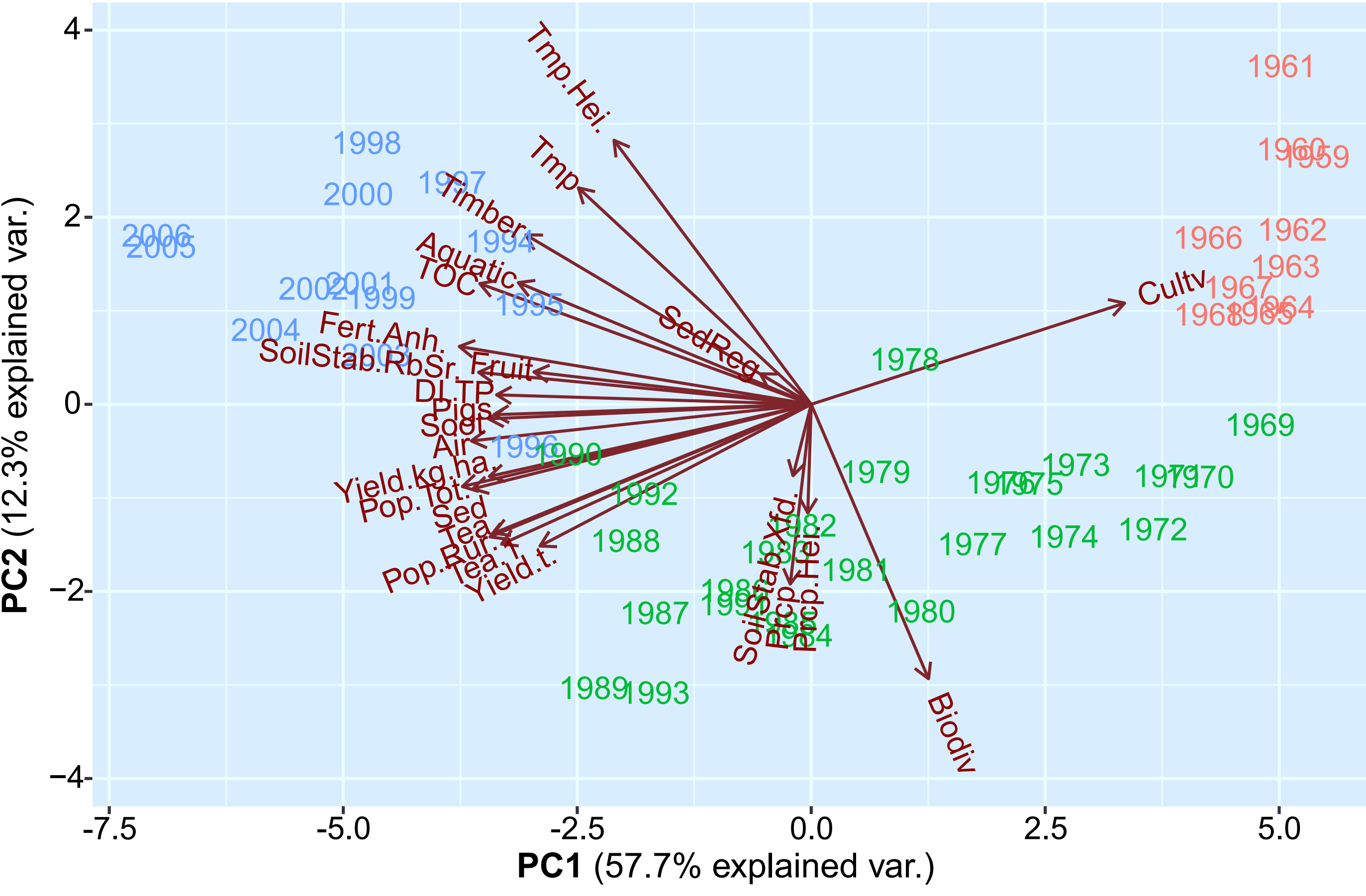


a)

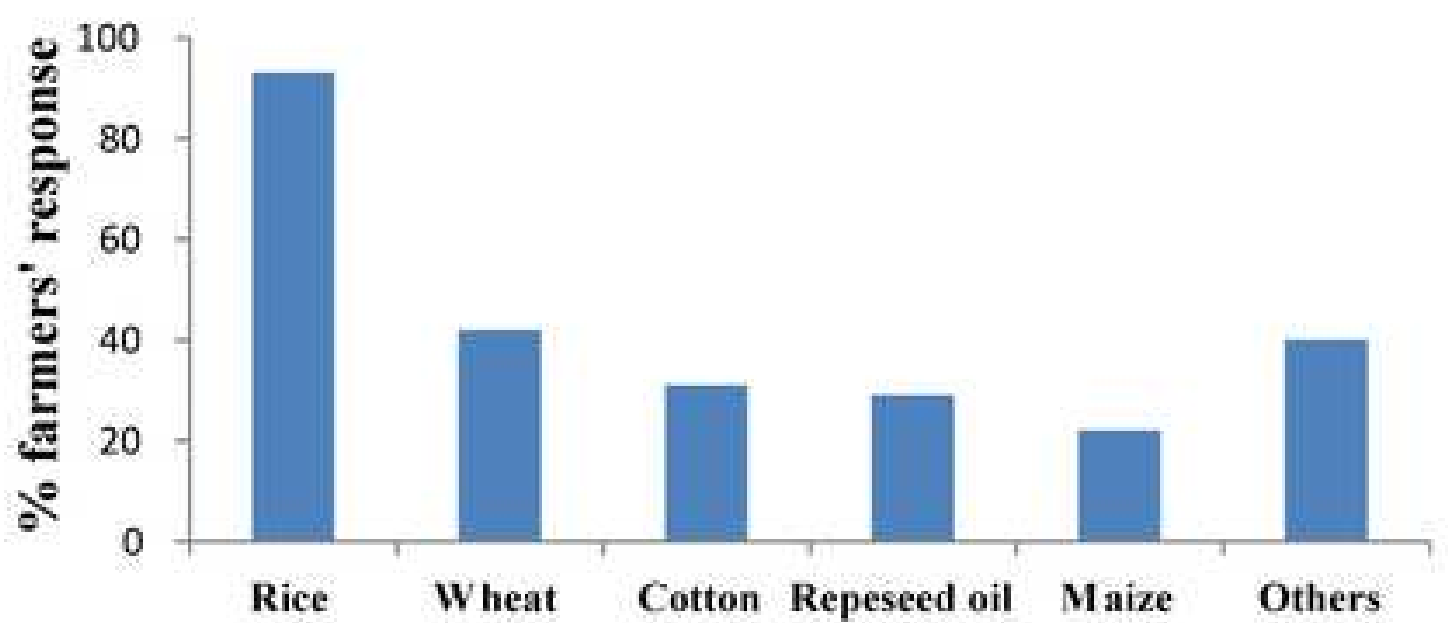

b)
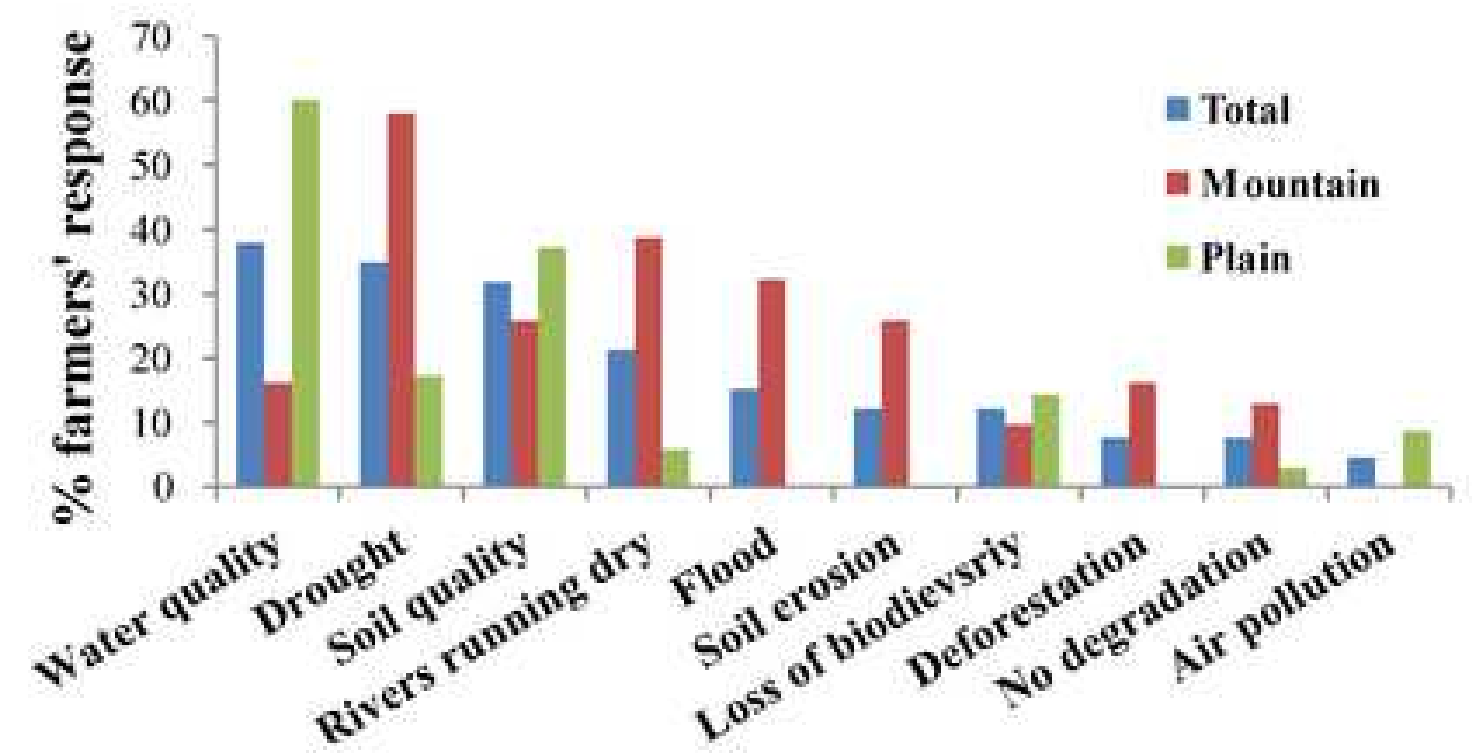

c)

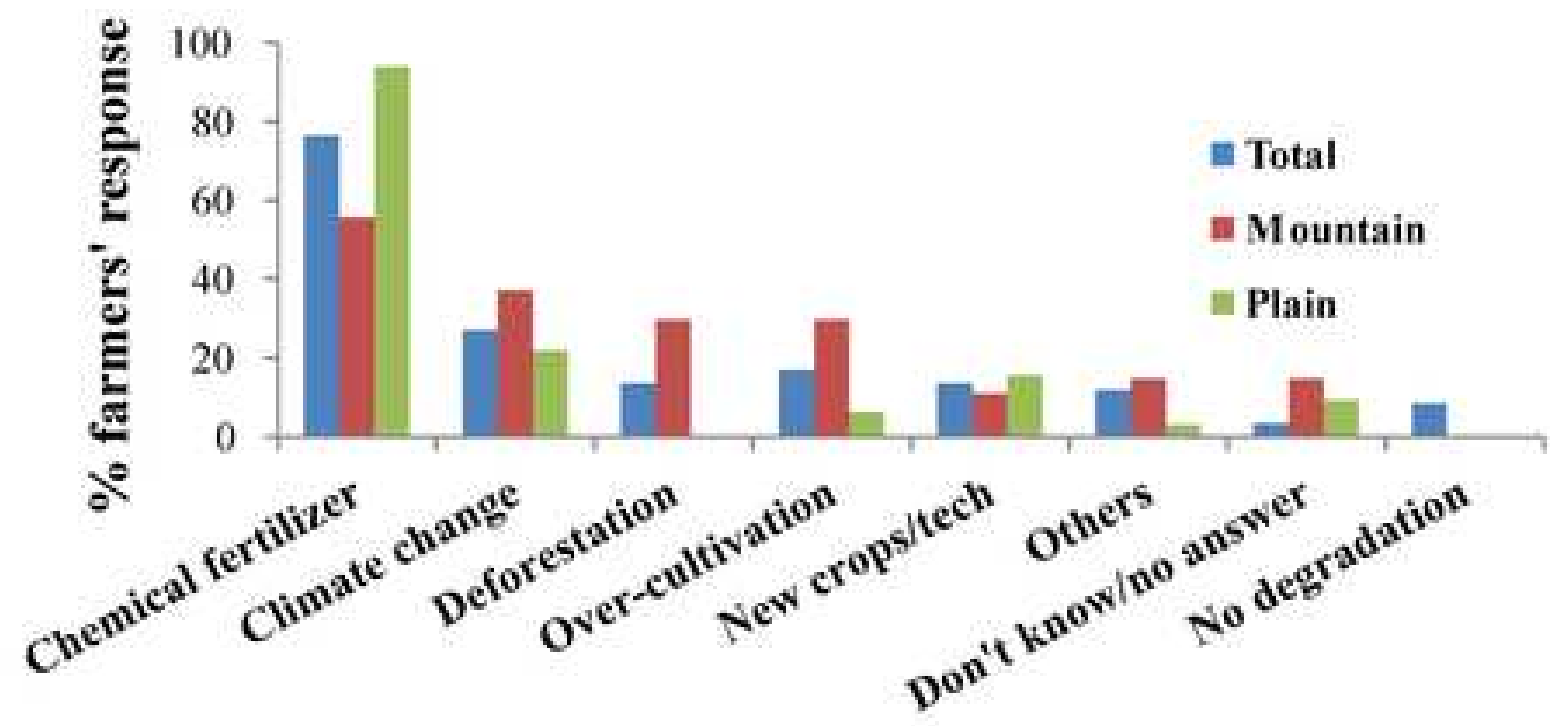



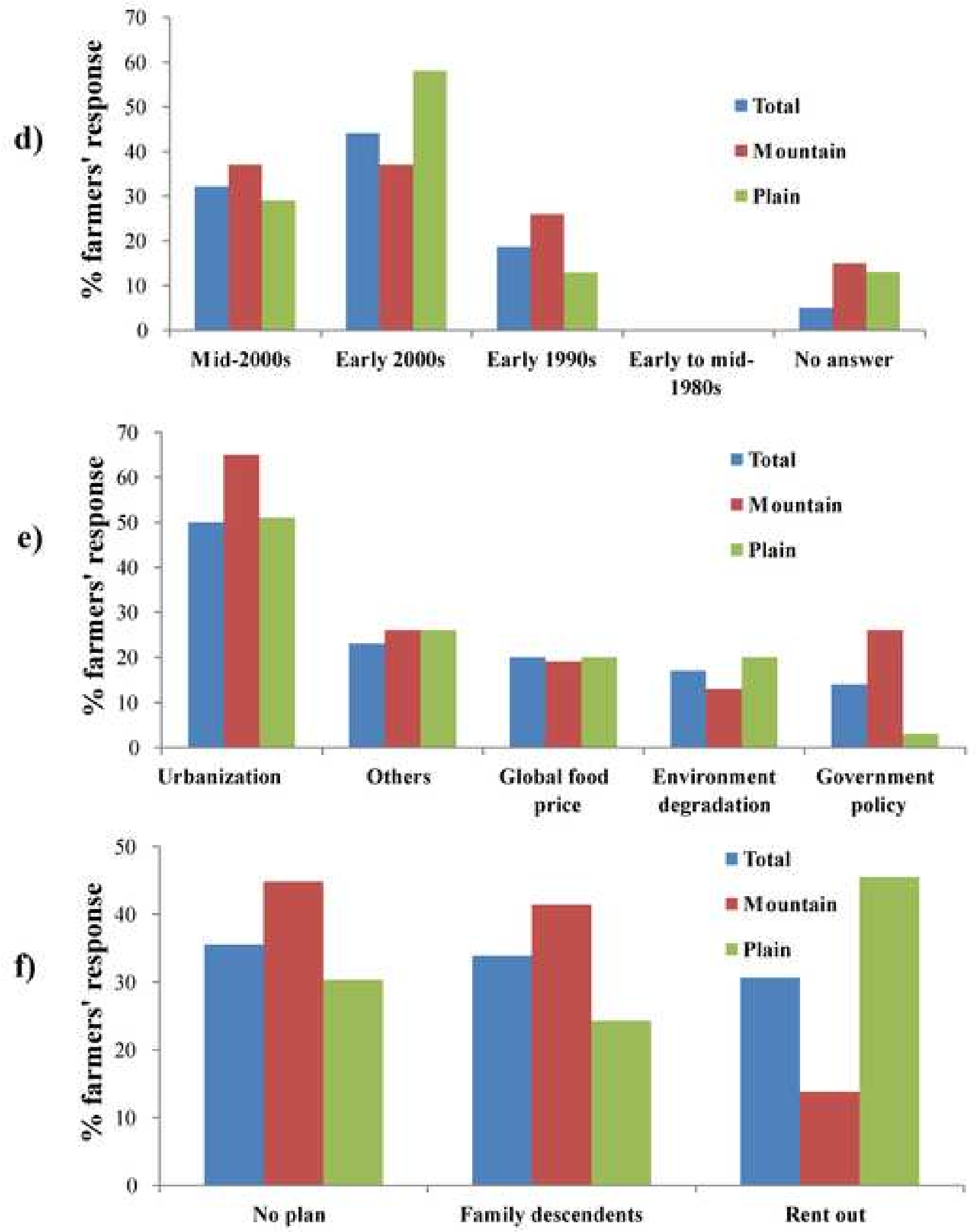